Federal Reserve Bank of Minneapolis

Research Department Staff Report 355

February 2005

\title{
Real Effects of Inflation Through the Redistribution of Nominal Wealth
}

\author{
Matthias Doepke* \\ University of California, Los Angeles, \\ Federal Reserve Bank of Minneapolis, \\ and Center for Economic Policy Research \\ Martin Schneider* \\ New York University
}

\begin{abstract}
This paper provides a quantitative assessment of the effects of inflation through changes in the value of nominal assets. We document nominal positions in the U.S. across sectors as well as different groups of households, and estimate the redistribution brought about by a moderate inflation episode. Redistribution takes the form of "ends-against-the-middle:" the middle class gains at the cost of the rich and poor. In addition, inflation favors the young over the old, and hurts foreigners. A calibrated OLG model is used to assess the macroeconomic implications of this redistribution under alternative fiscal policy rules. We show that inflation-induced redistribution has a persistent negative effect on output, but improves the weighted welfare of domestic households.
\end{abstract}

\footnotetext{
*The authors would like to thank Orazio Attanasio, Harold Cole, Ellen McGrattan, Mark Gertler, Lee Ohanian, Monika Piazzesi, José-Víctor Ríos-Rull, Thomas Sargent, Harald Uhlig, Gianluca Violante, Warren Weber, Randall Wright and seminar participants at Duke, the Federal Reserve Bank of Minneapolis, Frankfurt, Haifa, Hebrew University, IIES, Iowa, Mannheim, Montréal, the NBER Summer Institute 2004, Northwestern, NYU, Pennsylvania, Rutgers, UCLA, UC Santa Barbara, UQAM, Tel Aviv, and the SED and SITE 2003 conferences for helpful comments. Juan Pablo Medina provided excellent research assistance. Addresses: Doepke, Department of Economics, University of California, Los Angeles, 405 Hilgard Ave, Los Angeles, CA 90095-1477 (email: doepke@econ.ucla.edu). Schneider, Department of Economics, New York University, 269 Mercer St., 7th floor, New York, NY 10003 (email: ms1927@nyu.edu). The views expressed herein are those of the authors and not necessarily those of the Federal Reserve Bank of Minneapolis or the Federal Reserve System.
} 
An immediate consequence of an unanticipated change in the price level is redistribution: inflation lowers the real value of nominal assets and liabilities, and thereby redistributes wealth from lenders to borrowers. Recent literature on the real effects and welfare costs of inflation has paid little attention to redistribution effects. While representative-agent models provide no scope for redistribution at all, existing studies with heterogeneous agents focus on the effect of inflation on cash balances alone, which make up only a minor fraction of all nominal assets. ${ }^{1}$

This paper provides a quantitative study of the redistribution effect of inflation. We focus on the question of what would happen if the United States were to enter another inflation episode such as the one experienced during the 1970s. We emphasize the role of money as a unit of account: inflation affects all nominal asset positions, not just cash positions. As a result, we find that even moderate inflation leads to substantial wealth redistribution.

Since wealth changes induce agents to adjust their behavior over the entire life cycle, the effects on individuals are persistent. Moreover, the responses of losers (old lenders) and winners (young borrowers) do not cancel out, so that aggregates react as well. The magnitude of the aggregate effects is comparable to those in representative-agent models with monetary frictions, but the effects arising from redistribution persist long after the end of the inflation episode.

We also find that the welfare effect on domestic households arising from redistribution is the opposite of what standard monetary models generate: inflation-induced redistribution leads to a positive effect on weighted aggregate welfare. Financial innovation and foreign borrowing have recently increased the potential welfare gains from inflation, to the point that these gains are now substantially larger than conventional estimates of the welfare cost of inflation. We conclude that redistribution is a key channel for the impact of inflation on household behavior, economic aggregates, and welfare.

We arrive at our conclusions by performing the following thought experiment. Suppose an economy is initially in a low-inflation regime, as is the case for the U.S. today. Suppose further that an episode of moderate inflation, such as the 1970s, were to occur. If all real effects of inflation were due to the redistribution (i.e., the only role of money is to serve as a unit of account for assets and liabilities), who would gain and who would lose during this episode, and what economic effects would arise? We answer these questions in three steps. First, we document nominal asset and liability positions in the U.S. economy for various groups of households, as well as the government and foreign sectors. Second, we estimate the redistribution of wealth generated by a moderate inflation episode under various assumptions on agents' expectations of — and adjustment

\footnotetext{
${ }^{1}$ There is an old tradition in monetary economics that does focus on redistribution-see Fisher (1933) for a classic contribution.
} 
to-inflation during the episode. Third, we use a calibrated overlapping-generations model to assess aggregate effects and welfare costs under different scenarios for fiscal policy, as well as the behavior of foreigners.

To determine nominal positions, we combine data from the Flow of Funds Accounts (FFA) and the 1989 and 2001 Surveys of Consumer Finances (SCF). We consider not only directly held nominal assets and liabilities, but also indirect nominal positions due to shares in investment intermediaries and the ownership of firms. For most securities, the data consist of book values that are difficult to interpret. We thus construct the stream of future nominal payments associated with every major class of securities, and then restate all positions at market value. With this approach we can estimate the duration of agents' positions, which allows us to gauge the effects of partially anticipated inflation.

We document several stylized facts on net nominal positions that are crucial for understanding redistribution effects of inflation. First, indirect debt positions through equity holdings are an important part of households' overall nominal position. Second, foreigners are a major net nominal lender, especially in the last 15 years. Once indirect debt positions are taken into account, foreigners now hold more U.S. nominal assets than domestic households. Third, in the cross-section of households, young middle-class cohorts with mortgage debt are the only important net nominal borrowers. Young rich and poor households, as well as the old at all income levels, are net nominal lenders.

We perform most of our inflation experiments for a benchmark low inflation year, 1989. We compute real gains and losses resulting from a change in the unit of account. The size of that change is motivated by the U.S. experience of the 1970s: we consider a return of the ten-year inflation episode 1973-1982. Our experiments are calibrated to capture different scenarios for how agents adjust expectations and portfolios during the episode. This leads us to interval estimates for gains and losses of different sectors and groups of agents. A coalition of rich, poor and old households loses a total of 6.6-17.6 percent of GDP in present value terms. Roughly one-half of this loss benefits middle-class households under the age of 45, who receive a gift worth up to 60 percent of mean cohort net worth. The remainder goes to the government, which gains between 5.2 and 14.1 percent of GDP through a reduction in the real value of its debt.

To assess the aggregate effects of redistribution, we employ a deterministic neoclassical growth model with overlapping generations. The model is calibrated so that its balanced growth path matches key aggregate ratios, as well as properties of the wealth and income distribution. To explore the economy's response to an inflation episode, we treat the transfer of real wealth computed 
in our redistribution exercise as an unanticipated shock. Since the model is designed to isolate the redistribution effects of inflation, we abstract from monetary frictions. Instead, aggregate effects of inflation derive from two sources: direct wealth effects on the different groups of households, and the response of fiscal policy. Fiscal policy must adjust in some dimension, since the reduction of real government debt presents the government with a windfall gain. We use our model to explore the response of the economy for a number of different fiscal policy rules.

Even though the redistribution shock is zero-sum, aggregate effects arise because net borrowers (winners) and net lenders (losers) respond differently. The key asymmetry in nominal positions is that net borrowers tend to be younger than net lenders, which gives rise to two life-cycle effects. First, a reduction in the labor supply of the young winners (that is, an increase in their consumption of leisure motivated by an increase in wealth) is not offset by an increase in labor supply by the old losers, since the latter are retired. Second, an increase in the savings of the young winners is not fully offset by a decrease in the savings of the old losers, since young households spread any gain or loss over more remaining periods of life than old households. In our calibrated model, the first effect causes aggregate labor supply to decline by up to 1.5 percent in the decade after the inflation episode. The second effect increases the capital stock by up to 0.8 percent above trend three decades after the inflation episode. The net result is a decline in output over the first three decades after the shock of up to 0.8 percent relative to trend, followed by a smaller temporary increase.

The effects on the welfare of individual cohorts are large. Retirees lose the most and experience a decrease in their consumption of up to 12 percent relative to the balanced growth path. In contrast, consumption of the young middle-class cohorts increases by up to 6 percent. Domestic households also gain at the expense of foreigners. Using standard weighted welfare measures, we find that the aggregate welfare effect of inflation on domestic households is positive. This would be true even if foreigners were not affected by inflation, since the redistribution effect tends to level the overall wealth distribution. However, the losses incurred by foreigners substantially increase the positive welfare effect.

Throughout, we emphasize that redistribution effects depend on how quickly agents adjust to inflation. In our experiments, we distinguish surprise inflation episodes, during which the duration of positions is irrelevant, from gradual inflation episodes, where gains and losses are relatively larger on positions of longer duration. In addition to the overall nominal position, the maturity structure of assets and liabilities is a second important determinant of the redistribution effect of inflation. The main result is that gradual inflation episodes hurt foreigners and rich domestic households relatively more than other groups. The foreigners and the rich hold more long-term bonds than poor 
and middle-class households, whose nominal assets are mostly in the form of short-term deposits. We also show how financial innovation and an increasing nominal position of foreigners have recently led to large changes in the potential effects of inflation. In the last 15 years, inflation risk has become more evenly distributed across different groups of households. This is partly due to more widespread equity ownership, which has provided more gains through indirect debt to the poor. Another reason is that securitization has reduced the maturity mismatch in the financial system, and hence shifted the risk of gradual inflation from shareholders to bondholders. Securitization has also contributed to a decline in the net nominal position of the U.S. business sector, which is mirrored by a corresponding increase in the net nominal position of foreigners. The net nominal position of the rest of the world is currently around 30 percent of GDP, while the net nominal position of U.S. households (who own most of the business sector) approaches zero.

The implications of these changes can be gauged by comparing our results for the benchmark year 1989 to outcomes based on data from 2001. We find that gains and losses under surprise and gradual inflation are more similar in 2001 than they are in 1989; recent changes in financial structure make it harder for agents to adjust quickly to inflation. Particularly hard-hit by inflation are foreigners, who by 2001 have become the main net lenders in the economy, and who hold mostly long-term bonds. As a consequence, while the government's gain is similar for the two benchmark years, in 2001 the main loser is the rest of the world, with losses between 5.8 and 13.4 percent of GDP. These losses translate into substantial welfare gains for domestic households, so that, in terms of redistribution, inflation emerges as a highly attractive proposition from a U.S. perspective.

In the next section, we review the literature. Section 2 presents the distribution of nominal assets and liabilities in the U.S. economy. Section 3 quantifies the effect of an inflation shock. Section 4 presents and calibrates the theoretical model, which is used in Section 5 to analyze the economic implications of an inflation shock. Section 6 concludes.

\section{Related Literature}

One of the redistribution effects that underlies our results is the surprise revaluation of nominal government debt. This effect also matters in Bohn's (1988) study of fiscal policy. Bohn considers a stochastic model with incomplete markets where government debt is nominal. Nominal debt then provides insurance against the effects of economic fluctuations on the government's budget. A negative productivity shock leads to an increase in the price level (through the quantity equation), 
and thereby deflates the value of existing government debt. This windfall enables the government to continue to provide its services without being forced to raise taxes in the downturn. Nominal debt therefore serves as a mechanism that implements event-contingent insurance. ${ }^{2}$

Persson, Persson, and Svensson (1998) are also interested in the effect of inflation on government finances. For the case of Sweden, they conduct a thought experiment that is similar in spirit to ours: what would be the present value change in the government budget, as of 1994, if there was a permanent 10 percentage point increase in inflation? They find a sizeable effect, about as large as 1994 GDP. However, most of this effect is accounted for by incomplete indexation of the tax and transfer system, as opposed to the direct devaluation of government debt. Despite the large positive impact on the government's budget, the authors conclude that the net social gains of the inflation policy are likely to be negative. Burnside, Eichenbaum, and Rebelo (2003) examine the fiscal implications of currency crises in three middle-income countries. They find that devaluation of the dollar value of government debt is a more important source of depreciation-related government revenue than seigniorage, which is the source emphasized by most standard currency crisis models.

A connection between inflation and the wealth distribution can also arise through asymmetric incidence of the inflation tax. Erosa and Ventura (2002) observe that poor households hold more cash relative to other financial assets than rich households do. They rationalize this fact in a monetary growth model where access to credit markets is costly. The poor then pay a disproportionate share of the inflation tax and are hurt more by inflation. Since inflation acts like a nonlinear consumption tax-with higher rates for the poor-it also encourages precautionary savings and thereby leads to higher concentration of wealth. Albanesi (2002) derives a positive correlation between inflation and inequality in a similar model, where the inflation tax rate is set in a political bargaining game. Since the poor are more vulnerable to inflation, their bargaining power is weak and the rich succeed in implementing high inflation. The key difference between the inflation tax literature and our paper is that the former deals with the effect of anticipated inflation on cash holdings. In contrast, we are concerned with unanticipated shocks on all nominal asset holdings, of which cash holdings are only a small part.

Our paper is also related to a large literature on the link between the earnings and wealth distributions in the U.S. The key stylized fact that this literature has wrestled with is that the distribution of wealth is much more concentrated than that of earnings (see Budría Rodríguez, Díaz-Gimenéz, Quadrini, and Ríos-Rull 2002 for an overview of the stylized facts). Both models with dynastic households (for example, Aiyagari 1994, Krusell and Smith, Jr. 1998, Quadrini 2000) and

\footnotetext{
${ }^{2}$ See also Bohn (1990b) for some empirical evidence on this mechanism, and Bohn (1990a, 1991) on open-economy extensions.
} 
life-cycle models (Hubbard, Skinner, and Zeldes 1995, Huggett 1996) have been explored. More recently, several papers have combined features of these two setups by accommodating both lifecycle concerns for saving and altruism (for example, Castañeda, Díaz-Gimenéz, and Ríos-Rull 2003, De Nardi 2004, Laitner 2001).

Our model is simpler than those in most of the above studies in that households face no uncertainty. In particular, idiosyncratic labor income risk, the typical source of heterogeneity in the literature, is absent from our setup. Instead, all earnings heterogeneity is due to differences in deterministic skill profiles across types of households, and wealth inequality is partly generated by preference heterogeneity. We choose a different modeling strategy in order to be able to calibrate the model to observed features of specific groups of households, as opposed to aggregate moments of the earnings and wealth distribution. At the same time, our model shares several broad themes with existing studies. One is the importance of bequests for generating a group of rich households that holds most of aggregate wealth. In our model, agents with high earnings also have a greater 'warm glow' taste for transfers to their children. This may be viewed as a simplified version of the setups in Carroll (2000) and De Nardi (2004), who employ preferences where bequests are a luxury good. A second model feature that helps reconcile the different properties of the earnings and wealth distribution is the presence of a social security system.

Our model also has two features that are not staples of the wealth distribution literature. One is the explicit treatment of durables (both consumer durables and houses), which allows a distinction between financial and nonfinancial wealth. In addition, we assume that labor supply is endogenous, and we calibrate both earnings and wealth observations to a cross section of SCF data. In this respect, we follow Castañeda, Díaz-Gimenéz, and Ríos-Rull (2003). In contrast, most other studies work with an exogenous earnings process estimated from panel data. ${ }^{3}$

\section{Nominal Assets and Liabilities in the U.S. Economy}

Our methods for constructing nominal positions in the U.S. are described in detail in a separate appendix to this paper (Doepke and Schneider 2004). Here we describe the organizing framework, summarize the main steps of the calculations, and present the results. By nominal assets and liabilities we mean those denominated in U.S. dollars. We define the net nominal position of an agent (for example, a sector or an individual household) as the market value of all nominal

\footnotetext{
${ }^{3}$ We do not use panel data since, unfortunately, common panel data sets contain little information about rich households, who are particularly prominent owners of nominal assets.
} 
assets minus the market value of all nominal liabilities. These positions include indirect nominal positions, which are due to claims on investment intermediaries and the ownership of firms.

\subsection{Indirect Nominal Positions and Valuation}

Ultimately, every nominal claim in the economy is owned either by households and non-profit organizations, by foreigners, or by the government. Some of this ownership is indirect, however, through ownership claims on businesses. It is convenient to treat investment intermediaries separately from other business. Here an investment intermediary is defined as a financial intermediary that issues only one type of claim, namely shares. Examples are mutual funds, bank investment trusts and defined contribution pension funds.

Indirect positions through ownership of investment intermediary shares can be calculated by assigning a fraction of the intermediary's portfolio to the agent. We define the zero leverage net nominal position $\mathrm{NNP}(0)$ as the sum of directly held nominal assets plus nominal assets held through investment intermediaries less nominal liabilities. If all firms in the economy held only real assets (such as physical and intangible capital) and had no nominal debt, then an agent's NNP(0) would be his true net nominal position.

We refer to ownership claims on businesses other than investment intermediaries as equity. Since the typical business both holds nominal assets and issues nominal debt, we need to make an assumption on how the value of equity depends on inflation. We follow Hall (2001) and McGrattan and Prescott (2004) in adopting a frictionless approach to the valuation of the aggregate business sector. Let net equity denote the market value of all equity claims on U.S. businesses not held by other U.S. businesses. We assume that it is equal to the value of real assets held by firms plus firms' net nominal position at market value (which is negative if firms are net debtors):

$$
\text { Net Equity }=\text { Real Assets of Business Sector }+ \text { NNP (0) of Business Sector. }
$$

We define the net nominal leverage ratio $\lambda$ as the indirect net nominal debt position per dollar of equity held:

$$
\lambda=-\frac{\operatorname{NNP}(0) \text { of Business Sector }}{\text { Net Equity }} .
$$

This ratio is similar to a debt-equity ratio. It differs from conventional measures because it only incorporates nominal claims, and because debt is net of all nominal assets, including nominal assets held indirectly through investment intermediaries. 
The overall net nominal position now can be computed by adding the indirect position to the zeroleverage position:

$$
\operatorname{NNP}(\lambda)=\operatorname{NNP}(0)-\lambda(\text { Equity Held) }
$$

For any agent, this number summarizes exposure to purely nominal events in the economy. Changes in the price level affect the real value of payments that enter NNP $(\lambda)$. In addition, changes in inflation expectations affect the nominal yield curve and hence change both the direct position and the leverage ratio. The only part of financial wealth that is not affected by inflation or changes in inflation expectations is the claim on real business assets, which is equal to $(1+\lambda)$ (Equity held).

Throughout this section, we only consider claims to future nominal payoffs that are fixed by contract between a borrower and a lender. We do not include positions that arise because of future nominal tax obligations. The reason is that future tax rates are uncertain and are themselves likely to change as the result of an inflation episode. Indeed, any inflation episode entails revaluation of nominal government debt, so that fiscal policy must change to satisfy the government budget constraint. It is thus difficult to make statements about tax-induced positions outside of a model that can consider complete scenarios for fiscal policy. We thus relegate any tax effects to Sections 4 and 5 .

\subsection{Data}

Our principal data source for sectoral positions is the Flow of Funds Accounts of the United States (FFA), which provides a detailed breakdown of assets and liabilities for the household, business, foreign, and government sectors, as well as for various types of financial intermediaries. We use quarterly FFA data from 1952:1 to 2002:1. For household positions, we rely on the 1989 and 2001 editions of the Survey of Consumer Finances (SCF), which offers detailed information on income and wealth for a representative cross section of U.S. households.

We define sectors by aggregating FFA sectors and, in some cases, adjusting FFA definitions, as explained in the appendix (Doepke and Schneider 2004). The government sector comprises the Treasury, state and local government, the Federal Reserve System, and government-sponsored retirement funds. The foreign sector contains not only the FFA 'Rest of the World' sector, but also foreign-owned banks and funding corporations. Our household sector differs from the FFA in that we do not include the current value of defined benefit pension funds. We treat defined benefit pension assets as assets of the plan sponsor-the government or the business sector-rather than the plan beneficiary. 
Our business sector aggregates all business other than investment intermediaries. 'Equity' is thus a diversified claim on the aggregate business sector. The FFA does distinguish, however, between equity in corporate and noncorporate business, and our sectoral calculations use separate values of the leverage ratio $\lambda$ when computing indirect positions. We also distinguish financial and nonfinancial business when interpreting the results below.

For the most part, we use the same instrument categories as the FFA. For some instruments, we use additional data sources to supplement the FFA numbers. For example, we use the Life Insurers' Fact Book to determine the size of life insurers' separate account that backs rate-dependent instruments such as variable annuities. We also use the Survey of Current Business to obtain market value estimates of foreign direct investment in the U.S. Moreover, we only incorporate financial assets where we can identify both borrower and lender. This is in contrast to the FFA, where the corporate sector is credited with significant "miscellaneous financial assets." The latter includes accounting items such as goodwill that are not claims on a counterparty.

The SCF provides survey responses from around 3,500 households together with weights that produce U.S. aggregates. The sample design is particularly well-suited for our purposes since it oversamples rich households, who hold most assets. We use 1989 as one benchmark year because it is the earliest year with relatively low inflation for which the SCF is available. In addition, we use the 2001 edition, which is the most recent version of the SCF.

For the benchmark years 1989 and 2001, we combine the SCF and FFA data to obtain one consistent data set where every nominal asset position of a household or sector corresponds to an offsetting nominal debt position elsewhere in the economy. To arrive at this data set, we adjust some FFA aggregates to reconcile them with the SCF numbers. We estimate indirect positions at the household level with the help of nominal leverage ratios derived from the FFA. We also use supplementary FFA tables to infer indirect positions that SCF households hold in IRAs.

\subsection{Payment Streams and Market Value}

For most securities, positions in the FFA and SCF are stated at par value. The par values are not economically meaningful and are not comparable across securities of different maturities. We address this issue by constructing the payment streams that correspond to each asset. For every major class of security and every year $t$, we are interested in the sequence of future dollar payments

$\nu^{i}=\left\{v_{t, s}^{i}\right\}_{s=1}^{\infty}$ that the typical owner of the security expects to obtain as of the end of year $t$. We estimate payment streams by combining par value information from the FFA with data on 
maturities and coupon interest rates. We do this separately for several major instrument categories. For bonds, we distinguish Treasury securities, municipal securities, corporate bonds, agency bonds, mortgage-backed securities, as well as a large number of short-term securities. For any bond traded at $t$, the payment $v_{t, s}^{i}$ comprises coupon and principal payments that are expected at $t+s$.

For loans, we distinguish mortgages from other loans, such as business and consumer credit. The payment $v_{t, s}^{i}$ on a loan outstanding at $t$ consists of amortization and interest payments due at $t+s$. Our estimation of those payments accommodates both repricing and prepayment. For example, when we construct payments streams on adjustable rate mortgages, we take into account the dependence of payments on changes in interest rates. For fixed-rate mortgages, we build in assumptions on refinancing, which is expected to take place when nominal interest rates fall.

Given the payment stream expected for an instrument beginning of year $t$, we calculate the market value of the instrument by discounting the payment stream with the nominal zero-coupon yield curve for $t$. Let $i_{t, s}$ denote the continuously compounded nominal yield to maturity in year $t$ on a zero-coupon bond that pays one dollar at $t+s$. The market value of the instrument as of year $t$ is then given by:

$$
\sum_{s=1}^{\infty} \exp \left(-i_{t, s} s\right) \nu_{t, s}^{i} .
$$

We use this formula to derive market value adjustment factors that can be applied to all FFA and SCF positions, by year and instrument class. The resulting nominal positions at market value are discussed in the next two subsections.

\subsection{The Evolution of Nominal Positions by Sector}

Figure 1 summarizes the evolution of nominal positions from 1952 to 2002 . The figure shows the net nominal positions $\operatorname{NNP}(\lambda)$ of the three ultimate claimants of nominal assets and liabilities: domestic households, the rest of the world, and the government. All positions are stated as a fraction of GDP. ${ }^{4}$

It is apparent from Figure 1 that there was a structural break in U.S. nominal positions around 1980. Before 1980, the position of the rest of the world was near zero. The positions of the government and the households were mirror images, with the government being the major borrower (negative

\footnotetext{
${ }^{4}$ Since the $\operatorname{NNP}(\lambda)$ already contain indirect positions through claims on businesses, they add up to the discrepancy of the FFA plus the holdings of nonprofit organizations, which together are close to zero.
} 
NNP) ${ }^{5}$ and the households being the lender (positive NNP). The positions declined steadily from around 50 percent of GDP in the early 1950s to around 20 percent in 1980. After 1980, two things changed. First, nominal claims began to grow more quickly, resulting in a large increase in government borrowing relative to GDP. Second, the rest of the world started to become a major net lender. Over the last 20 years, foreigners have built a net nominal position of up to 30 percent of GDP. ${ }^{6}$ The rest of the world is now the only major net creditor among end-user sectors, while the government is the major net debtor. Meanwhile, the net position of U.S. households is close to zero.

Figure 2 provides a breakdown of different classes of instruments and direct versus indirect positions. Here the item "short instruments and loans" collects short-term claims such as deposits and commercial paper together with non-mortgage loans. The instruments in this class mostly have maturity (or time to repricing) of less than one year. The panel on "bonds" aggregates government debt, corporate bonds and mortgage-backed securities. The scale is the same across all four panels of Figure 2, so that the positions in the instrument panels sum to those in the top left (aggregate) panel. In every panel, the three black lines depict the $\operatorname{NNP}(\lambda)$ of the three end-user sectors: U.S. households, the rest of the world, and the U.S. government. To illustrate the importance of indirect positions, the grey line shows the $\mathrm{NNP}(0)$ of the household sector. The total indirect position of the household sector is then given by the difference between the solid black and the grey line. This position is negative - households are indirect debtors — and amounts to up to 25 percent of GDP.

Figure 2 provides further insights into the changes in U.S. nominal positions that occurred after 1980. Longer maturity claims have become more important for intersectoral borrowing and lending. In particular, consider the net position of the household sector. Figure 2 shows trend breaks in net mortgage and bond positions, while the net short position remains stable at first, and actually declines in the 1990s. This reflects two developments in the financial system. On the one hand, households have been increasing savings for retirement through pension plans and mutual funds. Their resulting indirect nominal holdings are more tilted towards long-term bonds than traditional direct holdings of deposits. On the other hand, securitization of mortgage markets implies that a lot of mortgages are now financed by bond issues. The financial sector was traditionally a net holder of bonds and mortgages, and a net issuer of short instruments. Around 1985, however, the financial sector became a net issuer of bonds. By the year 2000, the value of outstanding bonds amounted

\footnotetext{
${ }^{5}$ Notice that the ratio of the government's $\mathrm{NNP}(\lambda)$ to GDP is not identical to a standard debt/GDP ratio, because the $\operatorname{NNP}(\lambda)$ nets out all direct and indirect holdings of nominal assets.

${ }^{6}$ This position consists about equally of bond and mortgage holdings, while short instruments are less important. Notice that the rest of the world sector contains not only foreign private investors, but also foreign institutions, particularly private banks and central banks. Mortgage holdings reflect direct issues by foreign banks, as well as indirect ownership of mortgage assets through equity claims on U.S. banks.
} 
to 40 percent of GDP, which accounts for the large indirect bond position of the household sector. About half of these bonds are mortgage-backed by loans in federally-related mortgage pools. Since net outstanding short debt of the financial system decreased in the 1990s, it is apparent that the recent surge in mortgage lending was mostly financed by bonds.

This transformation has led to a reduction in the maturity mismatch of the financial system. Traditionally, banks used to hold long-term assets and short-term liabilities. More recently, long-term mortgage loans have been financed by bonds. This change affects the indirect position of shareholders. In Figure 2, domestic shareholders' indirect position due to different instruments can be read from the difference between the solid black and the grey line. Shareholders are always long in mortgages and short in short-term instruments. However, the recent increase in their indirect mortgage position has been offset by a substantial short position in bonds. As a result, the portion of their net position that is subject to a maturity mismatch has declined.

\subsection{The Cross-Section of Household Nominal Positions}

The SCF data allows us to add detail to the household sector by distinguishing different types of households. We are interested in heterogeneity along three dimensions: age, wealth, and use of credit markets. Households are first sorted, by age of the household head, into six cohorts: households under $35,35-45,45-55,55-65,65-75$, and over 75 . For each cohort, we refer to the top 10 percent of households by net worth as 'rich' households. The non-rich households are then sorted by the amount of debt they owe. We refer to those non-rich households whose market value of debt is above the median for non-rich households as the 'middle class,' and to the remainder as the 'poor.' The appendix shows that these labels make sense: our middle-class households have significantly higher net worth and earnings than our poor households. Our sorting by debt is motivated by the inflation experiment that we are working towards. The effect on a particular household depends primarily on whether that household is a debtor or lender. By grouping all high-debt households together, we can learn more about their characteristics. ${ }^{7}$

Table 1 presents household net nominal positions by age and wealth, together with a decomposition by instrument class. For every cohort, the average cohort positions have been normalized by cohort net worth. For comparison, the table also reports durables, equity and net financial asset positions. Here durables equals all nonfinancial assets recorded by the SCF minus business wealth. This position contains mostly real estate, and also consumer durables. Equity consists of direct and

\footnotetext{
${ }^{7}$ An alternative sorting by net worth or earnings yields similar stylized facts, that is, among the lower 90 percent the richer households have more debt.
} 
indirect holdings of public equity as well as the value of ownership claims on private businesses. The Net Financial Position (NFP) is defined as wealth net of durables. Ignoring a few minor items, it may be thought of as the sum of equity and the zero-leverage nominal position:

$$
\mathrm{NFP}=\text { Net Worth }- \text { Durables } \approx \text { Equity held }+ \text { NNP }(0) .
$$

Comparing asset allocation decisions across groups reveals a number of patterns. Middle-class households invest most of their wealth in durables (mostly houses). Early on in life, they partly finance these stocks of durables with large amounts of debt, especially mortgage debt. In contrast, the poor and rich have little debt, and a smaller fraction of their wealth is in the form of durables. Moreover, while net financial and net nominal positions are smaller for younger cohorts, few cohorts have negative net nominal positions. Only middle-class households under 55 as well as the youngest rich cohort are in this group.

Among the older (net lender) cohorts, there are differences in the duration of nominal asset holdings. Old rich households keep a large part of their nominal savings in bonds, whereas the old poor rely more on short instruments such as deposits. Another feature of the rich is that indirect debt due to equity holdings significantly reduces their net nominal positions at all ages. The old middle class is quite similar to the poor in terms of retirement savings choices, although they hold somewhat higher amounts of equity and bonds and fewer short instruments.

\section{Inflation and Redistribution}

Based on the nominal positions documented above, we want to assess the redistribution induced by a moderate inflation episode. Our goal is to estimate (for every sector and group of households) the present value of the gain or loss encountered if the inflation of the decade 1973-1982 were to return, beginning at the end of a given benchmark year. Both the scale and the nature of redistribution depend on how quickly agents adapt to the new inflation regime. On the one hand, the sooner agents anticipate the higher inflation and adjust their portfolios accordingly, the smaller any wealth effects will be. On the other hand, portfolio adjustment can protect short-term positions more effectively than long-term positions. As a result, faster adjustment implies comparatively larger effects on agents whose positions have longer duration. We do not take a stand on exactly how expectations are formed and portfolios are adjusted during an inflation episode. Instead, we construct two scenarios that provide upper and lower bounds on redistribution, and illustrate the qualitative implications of adjusting expectations. 
As a lower-bound scenario, suppose that the entire new inflation path is publicly announced at the end of the benchmark year. Bond markets will then adjust immediately, and higher expected inflation will be reflected in higher nominal interest rates. The new present value of nominal positions can be calculated by discounting agents' expected payment streams with the new nominal term structure. We call this scenario Indexing ASAP, because agents implicitly adjust as soon as possible to fully-indexed portfolios. The loss on a position in one-year bonds, say, is given by the change in the present value of a payment promised for next year. There is no loss on future oneyear investments made during the inflation episode, since higher interest rates fully compensate for inflation. In other words, money due from one-year investments is protected from inflation that occurs after the first year. ${ }^{8}$ The lack of inflation surprises after the initial announcement makes the Indexing ASAP scenario a lower bound for the absolute value of actual gains and losses. In addition, it implies that agents with longer duration positions experience relatively larger gains and losses.

Our upper-bound scenario is that neither inflation expectations nor portfolio positions change relative to the benchmark year during the inflation episode. At all times during the episode, the inflation up to that point is perceived as a temporary anomaly, and things are expected to return to normal the following year. Expectations therefore do not adjust, and portfolio positions as well as nominal interest rates remain unchanged. This Full Surprise scenario thus captures repeated inflation surprises, a common feature of actual inflation episodes. In this scenario, the percentage present value change is the same for all portfolio positions, regardless of maturity. The size of the change is determined by the difference in cumulative ten-year inflation between the 1973-1982 decade and the decade following the benchmark year. Under the Full Surprise scenario, gains and losses are not only larger than under Indexing ASAP, but also do not discriminate among agents with different portfolio duration. Under Full Surprise, agents do not adjust at all to inflation, while under Indexing ASAP they adjust as much as possible.

\footnotetext{
${ }^{8}$ For the wealth effects we are interested in, it does not matter exactly how agents achieve inflation protection for short positions. In practice, one could imagine reinvestment at a higher nominal interest rate or at the real interest rate, or alternatively earlier consumption. It is also irrelevant how the loss on longer term positions is realized. Since there is perfect foresight after the initial announcement, the wealth effects are the same whether bonds are sold at a loss early or whether they are held to maturity.
} 


\section{Computation and Interpretation of Gains and Losses}

It is convenient to represent the computations underlying both of our scenarios as adjustments to the nominal term structure, holding the real term structure fixed. ${ }^{9}$ Let $\imath_{t}^{n}$ and $r_{t}^{n}$ denote the total yields on $n$-year nominal and indexed zero-coupon bonds, respectively, in the benchmark year $t$. Suppose that the Fisher equation holds ex ante in the benchmark year, so that $\pi_{t}^{n}=\imath_{t}^{n}-r_{t}^{n}$ is cumulative expected inflation. Let $\tilde{\pi}_{t}^{n}$ denote the new inflation path realized from $t$ to $t+n$. The inflation factors for our baseline experiments with benchmark year 1989 are depicted in Figure 3. We take the real interest rate to be equal to the nominal rate minus realized CPI inflation, with the 2003 inflation rate used for expectations beyond 2003. ${ }^{10}$ The initial expectations $\pi_{t}^{n}$ are shown as the dashed black line starting in 1989. To obtain the new inflation path, we replace the first ten years of inflation implicit in $\pi_{t}^{n}$ by realized inflation starting in 1973. The resulting cumulative new path $\tilde{\pi}_{t}^{n}$ is shown as the solid grey line starting in 1989.

Under Indexing ASAP, the new inflation path is announced at the end of the benchmark year. The nominal yield curve thus immediately adjusts to $\tilde{\imath}_{t}^{n}=r_{t}^{n}+\tilde{\pi}_{t}^{n}$. To determine gains and losses, we revalue the payment streams associated with bonds and fixed rate mortgages using this new yield curve. Consider a position that promises a single payment $\nu_{t+k}$ in year $t+k$. The percentage loss on this position is $1-e^{-\left(\tilde{\pi}_{t}^{k}-\pi_{t}^{k}\right)}$. The difference between cumulative inflation paths (given by the difference between the solid grey and dashed black lines in Figure 3) is steeply increasing in maturity. This reflects the fact that the Indexing ASAP scenario allows for implicit adjustment by agents towards indexed portfolios. To see this, let $\tilde{l}_{t+k}^{10-k}$ and $r_{t+k}^{10-k}$ denote the $(10-k)$-year nominal and indexed forward interest rates quoted at $t$, respectively and let $\tilde{\pi}_{t+k}^{t+10}$ denote cumulative expected inflation from $t+k$ to $t+10$. Since the Fisher equation holds after the announcement, the present value of the position can be rewritten as:

$$
e^{-\tilde{\imath}_{t}^{k}} \nu_{t+k}=e^{-\tilde{\imath}_{t}^{10}}\left(\nu_{t+k} e^{\tilde{\imath}_{t+k}^{10-k}}\right)=e^{-\left(r_{t}^{10}+\tilde{\pi}_{t}^{10}\right)}\left(\nu_{t+k} e^{\left(r_{t+k}^{10-k}+\tilde{\pi}_{t+k}^{10-k}\right)}\right)=e^{-r_{t}^{10}}\left[\left(e^{-\tilde{\pi}_{t}^{k}} \nu_{t+k}\right) e^{r_{t+k}^{10-k}}\right] .
$$

In other words, once the payment is due at $t+k$, it may be thought of as reinvested at the forward rate $\tilde{l}_{t+k}^{10-k}$ which fully incorporates future inflation. Equivalently, in real terms, once the loss or gain from inflation up to $t+k$ has been realized, reinvestment takes place at the real rate.

The simplest way to think about the Full Surprise scenario is that all positions are multiplied by the

\footnotetext{
${ }^{9}$ The assumption that real interest rates do not move with redistribution is in line with the calibrated model in Section 5 below, where the redistribution shock has only a small effect on the real interest rate.

${ }^{10} \mathrm{An}$ alternative would be to estimate a time series model for inflation and use the forecast from that model. However, since inflation is very persistent, the results would be rather similar, at least after the high inflation of the 1980 s.
} 
same factor, $e^{-\left(\tilde{\pi}_{t}^{10}-\pi_{t}^{10}\right)}$. It thus represents revaluation in hypothetical situations where either the ten-year inflation occurs in one day, or, equivalently, where agents are not allowed to touch their portfolios for ten years. To see that similar outcomes are possible with rebalancing but repeated surprises, consider again the present value of a position that pays $\nu_{t+k}$ at date $t+k$. As under Indexing ASAP, the investor will take a loss as the real value of the payment at $t+k$ falls to $e^{-\tilde{\pi}_{t}^{k}} \nu_{t+k}$. Now suppose the payment is reinvested. Since agents hold on to their original inflation expectations $\pi_{t}^{k}$ as the inflation episode unfolds, the spot nominal interest rate on a $(10-k)$-year zero-coupon bond quoted at $t+k$ is $i_{t+k}^{10-k}$, which is unchanged from the forward rate quoted in the bond market at $t$. This interest rate does not offer full protection against the new inflation path $\tilde{\pi}_{t+k}^{10-k}$; there will be an additional surprise loss on the position after reinvestment. The present value can be written as:

$$
e^{-r_{t}^{10}}\left[\left(e^{-\tilde{\pi}_{t}^{k}} \nu_{t+k}\right) e^{\left(i_{t+k}^{10-k}-\tilde{\pi}_{t+k}^{10-k}\right)}\right]=e^{-\left(\tilde{\imath}_{t}^{k}+\left[\tilde{\pi}_{t+k}^{10-k}-\pi_{t+k}^{10-k}\right]\right)} \nu_{t+k}=: e^{-\left(\tilde{\imath}_{t}^{k}+s_{t}^{k}\right)} \nu_{t+k}
$$

The cumulative inflation factor for the Full Surprise experiment is represented by the dotted black line in Figure 3. The Full Surprise loss depends on the difference between the dotted and dashed black lines and has two parts. First, there is the loss under Indexing ASAP. For all payments due after ten years, this part makes up for the whole loss-there is no difference between the two experiments for long-term positions. In addition, there is the surprise loss $s_{t}^{k}:=\tilde{\pi}_{t+k}^{10-k}-p i_{t+k}^{10-k}$, incurred through reinvestment of short-term positions. It depends on the difference between the dotted black and solid grey lines and is decreasing in maturity-there are more surprise losses when reinvesting shorter term positions. Overall, the proportional loss on all positions is $s_{t}^{10}$.

Since the period length in our valuation framework is one year, the above discussion applies directly only to positions with maturity of one year or longer. We make analogous calculations for shorter claims. Under Indexing ASAP we assume that positions in deposits, non-mortgage loans and short term paper - all valued at par in our valuation exercise — can be adjusted within the first year of the inflation episode. The idea is that while it typically takes some time before loans can be repriced or deposits can be withdrawn, agents will try to earn a different interest rate as soon as possible. We devalue the par values by a six-month inflation surprise. Similarly, we devalue adjustablerate mortgages with a one-year inflation surprise. This captures the fact that, for most ARMs, adjustment can only occur at specific times. Under the Full Surprise experiment, all positions are multiplied by the same surprise inflation factor, namely $s_{t}^{10}=\tilde{\pi}_{t}^{10}-\pi_{t}^{10}$. By analogy, we also multiply deposit, non-mortgage loan, and ARM positions by that factor. ${ }^{11}$

\footnotetext{
${ }^{11}$ We assume indexing even on instruments for which current interest rates are zero, such as some checkable deposits. This is in line with the role of the Indexing ASAP scenario as a lower bound.
} 


\section{Redistribution across Sectors}

Figures 4 and 5 plot redistribution over time under the Full Surprise and Indexing ASAP scenarios, respectively. Both figures show aggregate effects as well as redistribution by class of instrument, following the structure of the position plots in Figure 2. The years on the x-axis now represent benchmark years for the start of a hypothetical inflation episode. Since the hypothetical inflation path is realized inflation from 1973-1982, the implied redistribution for the benchmark year 1973 is zero in both figures. In the Full Surprise case, all positions for a benchmark year $t$ are scaled by the same surprise factor $s_{t}^{10}$. Since the late 1980s, this factor has been approximately constant and implies a loss of roughly 45 percent per position. The top right panel of Figure 5 also illustrates the key difference between our two experiments: under Indexing ASAP, there is virtually no redistribution due to short instruments.

Among end-users, the government is the only winner, while the rest of the world (ROW) and domestic households lose. With net debt levels as high as in the 1990s, the government would gain at least 5 percent and up to 20 percent of GDP from a return of the 1970s. As of the late 1990s, inflation has become an elegant way to default on net foreign debt. A return of the 1970s now would amount to a gift from the ROW of at least 7 percent and up to 13 percent of GDP. Indirect positions also contribute to overall redistribution, especially since 1980. At the high levels of business debt of the late 1990s, the indirect gain via the stock market effectively offsets the direct loss made by households.

There are two interesting facts driven by duration. First, foreigners bear a larger share of losses in a gradual inflation episode, since the duration of the ROW position has typically been longer than that of domestic households. Figure 2 shows that while domestic households are net lenders in short term instruments and net creditors in (long term) mortgage markets, the opposite is true for the ROW. The negative net short position of the ROW reflects short term paper issued in the U.S. by foreign financial institutions as well as indirect short debt due to equity in U.S. businesses. As a result of these differences in duration, the ROW loses relatively more under Indexing ASAP, where short positions are not revalued. Comparison of the top left panels in the figures shows that this effect is especially large during the period 1982-1993. In this period, the ROW would have paid for more than half of the government's gain under the Indexing ASAP scenario, but for less than 40 percent under the Full Surprise scenario.

A second fact is that shareholders used to gain little in gradual inflation episodes, until the recent spread of securitization shifted more inflation risk to bondholders. This highlights again the transformation of the financial system over our sample period. In the traditional banking environment 
of the 1950s and 1960s, anticipated inflation would have implied losses on banks' fixed-rate mortgages and bond portfolios that could not be offset by gains on short liabilities. Since the corporate debt market was relatively small, the losses of the financial system would have led to a loss on the shareholders' overall indirect position. This explains why shareholders would have lost from our Indexing ASAP experiment in the 1960s (the solid black line is below the grey line during that time). In contrast, in the 1980s and 1990s, losses on mortgages are partly offset by gains on mortgage-backed securities. The increase in corporate debt in the late 1990s implies that by that time shareholders would have gained from anticipated inflation.

\section{Redistribution across Households}

Tables 2, 3, and 4 summarize the redistribution of wealth across sectors and groups of households, based on SCF data for the benchmark year 1989. The tables report the effects under both Full Surprise and Indexing ASAP. In Table 3, cohort gains and losses are stated in percent of mean group net worth, whereas in Table 4, they are stated as a fraction of total losses incurred by the household sector. The latter table thus makes gains and losses directly comparable across cohorts and serves as the basis for the "redistribution shocks" to be explored below in the context of our model.

As a general rule, inflation benefits young and middle-class households, while it hurts old, poor, and rich households. The gains to the young middle class arise mostly from debt relief on fixedrate mortgages. There is a smaller debt relief effect for the young rich, who have less debt as a percentage of net worth. To provide further perspective on magnitudes, net worth in 1989 was equal to 85 percent and 212 percent of annual earnings for the youngest and second-youngest middle class cohorts, respectively. Therefore, each of these cohorts gains between 19 and 50 percent of annual earnings. In 2003 dollars, the youngest middle class cohort gains between $\$ 9,100$ and $\$ 21,200$, whereas the 35-46-year-olds gain between $\$ 13,300$ and $\$ 36,200$. In aggregate terms, Table 4 shows that the four winner cohorts receive a transfer of 3.5-9.4 percent of GDP. The two youngest middle class cohorts pocket about 80 percent of this amount.

Who exactly pays for the losses depends crucially on the duration of the cohorts' portfolio, and on whether inflation is gradual. Consider first the effects for our benchmark year, 1989. Table 3 shows that the rich suffer relatively more from anticipated inflation, whereas the poor are hurt more by surprise inflation. Relative to net worth, the poor retirees lose most under the Full Surprise experiment, which hurts their saving deposits. The rich retirees hold a smaller share of their portfolio in nominal assets, so that their Full Surprise loss is smaller than that of the middle-class and poor 
retirees. However, to the extent that the rich do hold nominal assets, they invest more in long-term bonds. As a result, the Indexing ASAP experiment hurts the rich retirees more, in percent of net worth, than either the poor or the middle class. In terms of aggregates, the old rich households lose the most - the rich over 55 years of age account for 60 percent of total losses, or 4-10.5 percent of GDP. In 2003 dollars, the typical loss for a rich retiree below 75 years of age is between $\$ 100,000$ and $\$ 218,000$.

\section{The Effect of Financial Innovation in the 1990s}

Table 5 reports cohort gains and losses in percent of net worth for the benchmark year 2001. While anticipated inflation still favors the poor, the distribution of losses has recently become considerably more equal, especially when inflation is gradual. In percent of net worth, the poor now lose more than the rich under both experiments, the lone exception being the oldest cohort under Indexing ASAP. In aggregate terms, the rich's share in total losses under Indexing ASAP fell from 76 to 63 percent between 1989 and 2001, while the share of the poor rose from 14 to 22 percent. Under Full Surprise, the effects are smaller but go in the same direction: while the share of the rich remained constant at 59 percent of total losses, the share of the poor increased from 22 to 29 percent. The difference is mainly made up by the poor aged $45-75 .{ }^{12}$

Several developments in the financial system contribute to broader sharing of inflation risk. First, equity ownership has become more widespread. By 2001, equity as a fraction of assets had increased to 21, 19, and 48 percent for the poor, middle and rich groups, respectively, an increase of roughly 10 percentage points relative to 1989. The stock market gains in the Full Surprise case are thus shared more evenly among the three wealth groups. Due to an increase in business debt, gains due to indirect debt are also larger in 2001. For example, the 55-65-year old rich lose 9.7 percent of net worth on their direct holdings under Full Surprise, but gain 4.3 percent on their equity positions, for a total loss of only 5.4 percent of net worth. The poor of the same age cohort lose 11.9 percent of net worth on their direct holdings but still gain 2.3 percent on their equity positions, for a total loss of 9.6 percent. In contrast, in 1989 the same rich cohort won 1.5 percent through equity, while the corresponding poor cohort gained only 0.6 percent.

Moreover, reduction of maturity mismatch in the financial system and the increase in long-term

\footnotetext{
${ }^{12}$ The difference does not appear to be due to changes in demographics or cohort wealth distributions. The ratios of rich to poor net worth for the third through fifth cohorts were 24, 18 and 21, respectively, in 1989, while they were 26, 24 and 17, respectively, in 2001. For working savers, the wealth distribution thus became more unequal, while inflation losses became more equal. In addition, the distribution of losses across generations is quite similar in the two benchmark years.
} 
business debt have increased shareholder gains from gradual inflation episodes. Since the rich hold more equity, this also contributed to a more even distribution of gains and losses from gradual inflation across wealth groups. In contrast, the aggregate shift out of short savings instruments into longer term bonds appears to have affected all wealth groups similarly and has therefore not contributed to a shift of inflation risk. However, it has made the household sector as a whole more sensitive to gradual inflation. For example, Indexing ASAP losses of poor savers aged 45-75 were about 20 percent of their Full Surprise losses in 1989, but the ratio was one third in 2001. The same ratio for the rich rose from one half to two thirds. We thus conclude that financial innovation has both increased and redistributed the risk of gradual inflation episodes.

\section{The Model}

We now want to use an economic model to assess the macroeconomic implications of inflationinduced redistribution, as well as the welfare effects on different groups of households. The model is designed to exhibit the same dimensions of heterogeneity that characterize our data. Consequently, we use an overlapping generations model in which people differ both by age and by type, where the type will be calibrated to the "rich," "middle class," and "poor" groups in our data. Apart from predicting the reaction of firms and consumers, the model will also allow us to explore the role of government behavior. As documented above, the government is a major winner from inflation through the devaluation of government debt. We use the model as a laboratory to explore different reactions of the government to this windfall, such as lower taxes, higher government expenditures, or increased social security. We will see that the reaction of the government has important implications for who loses and who gains from inflation.

\subsection{Setup}

\section{Preferences}

We consider an overlapping-generations economy in which consumers live for $N+1$ periods, from 0 to $N$, and derive utility from durable and non-durable consumption. Every period, a cohort of size one is born. The utility function of a household of type $i$ born at time $s$ is:

$$
\sum_{t=s}^{s+N} \beta_{i}^{t} u_{i}\left(c_{i, s, t}, d_{i, s, t}, 1-l_{i, s, t}\right)+v_{i}\left(b_{i, s}\right),
$$


where $c_{i, s, t}$ is non-durable consumption, $d_{i, s, t}$ are houses (consumer durables), $l_{i, s, t}$ is labor supply, $1-l_{i, s, t}$ is leisure, and $b_{i, s}$ is the bequest left to the next generation. ${ }^{13}$ Preferences for bequests are of the "warm-glow" type, that is, parents derive utility directly from the bequest given to their children, as opposed to the children's utility.

The consumer receives a bequest in the first period of life, works for the first $N-1$ periods, and is retired during the last two periods. During retirement, the consumer receives a social security benefit from the government. Utility is maximized subject to the following budget constraints:

$$
\begin{gathered}
c_{i, s, s}+d_{i, s, t}+a_{i, s, s+1}=\left(1-\tau_{s}\right) w_{s} \phi_{i, 0} l_{i, s, s}+b_{i, s-N}, \\
c_{i, s, t}+d_{i, s, t}+a_{i, s, t+1}=(1-\delta) d_{i, s, t-1}+R_{t} a_{i, s, t}+\left(1-\tau_{t}\right) w_{t} \phi_{i, t-s} l_{i, s, t} \\
\text { for } s<t<s+N-1, \\
c_{i, s, s+N-1}+d_{i, s, s+N-1}+a_{i, s, s+N}=(1-\delta) d_{i, s, s+N-2}+R_{s+N-1} a_{i, s, s+N-1}+t r_{s+N-1}, \\
c_{i, s, s+N}+p_{s+N} d_{i, s, s+N}+b_{i, s}=(1-\delta) d_{i, s, s+N-1}+R_{s+N} a_{i, s, s+N}+t r_{s+N-1} .
\end{gathered}
$$

Here $a_{i, s, t}$ are savings, $R_{t}$ is the interest rate, $t r_{s+N-1}$ is a social security transfer, $w_{t}$ is the wage, and $\phi_{i, t-s}$ is an age- and type-specific skill parameter. Notice that the social security transfer is indexed by the first period of retirement, and is the same in both periods of retirement. In the last period, instead of buying houses outright, consumers rent the houses at price $p_{s+N}$. The rental units are owned by other households as part of their assets $a_{i, s, t}$, and the price of renting adjusts such that the return on owning houses is equal to the return on other assets. Equivalently, we could have assumed that rental services are supplied by a competitive industry that borrows money to build and rent out houses. We assume that young people buy houses, since otherwise the model could not match the observations that a large fraction of the population has positive net worth, but negative financial assets. At the same time, we assume that old people rent, so that we do not have to introduce additional assumptions on what happens to the houses of people after they die.

In a frictionless environment, owning a house and renting in a competitive market are equivalent. For a part of our analysis, however, we are going to assume that households face a borrowing constraint. In particular, households are only able to borrow up to a fixed fraction $\psi$ of the value of their houses:

$$
a_{i, s, t} \geq-\psi d_{i, s, t}
$$

\footnotetext{
${ }^{13}$ The explicit treatment of durables allows us to distinguish financial and nonfinancial wealth. The importance of durables for understanding life cycle patterns in consumption and wealth has been stressed by Fernández-Villaverde and Krueger (2001).
} 
As long as $\psi<1$, a financially-constrained household would be better off renting housing services instead of buying, as long as the housing market is competitive. We still maintain the assumption that young households buy their houses, because this is the prevalent situation in the data. This choice could be formally justified by introducing additional frictions (such as tax advantages) that favor buying over renting.

\section{Technology}

There is a competitive industry that produces the (nondurable) consumption good from physical capital $K$, intangible capital $E$, and efficiency units of labor $L$ according to the production function:

$$
Y_{t}=z_{t}\left(K_{t}^{\rho} E_{t}^{1-\rho}\right)^{\alpha} L_{t}^{1-\alpha}
$$

Output can be transformed into either type of capital or into the durable consumption good (houses) without adjustment costs. Both $K_{t}$ and $E_{t}$ are owned by households and rented to firms. Productivity $z_{t}$ grows at the exogenous and constant rate $g$ :

$$
z_{t+1}=(1+g) z_{t}
$$

Firms rent physical and intangible capital at the common rental rates $R_{t}$, and the depreciation rates are $\delta_{K}$ and $\delta_{E}$. In equilibrium, both types of capital have the same expected return. If in addition the two depreciation rates are the same, the two types of capital can be aggregated, and the model economy behaves just like the usual model with labor and physical capital only. Even in this situation, introducing intangible capital is useful for calibrating the model; in particular, we will be able to independently match the ratio of business capital $K_{t}$ to output and the return to capital to data.

Firms' first-order conditions equate the marginal product on either type of capital to its rental rate and the marginal product of labor to the wage rate. Due to the absence of arbitrage, the net returns on both types of capital must also be equal to the interest rate. We thus have:

$$
R_{t}=1-\delta_{k}+z_{t} \alpha \rho \frac{Y_{t}}{K_{t}}, \quad R_{t}=1-\delta_{E}+z_{t} \alpha(1-\rho) \frac{Y_{t}}{E_{t}}, \quad w_{t}=z_{t}(1-\alpha) \frac{Y_{t}}{L_{t}} .
$$




\section{Government and Foreigners}

There is a government which taxes labor income and issues debt to finance social security transfers, general government expenditures $G_{t}$, and interest on existing government debt $B_{t-1}$. The labor tax $\tau_{t}$ is linear, does not depend on the type of the worker, and may vary over time. The social security system consists of lump-sum payments $t r_{t-1}$ and $t r_{t}$ to every adult who retired in period $t-1$ and $t$, respectively. The period budget constraint of the government is:

$$
B_{t}+\tau_{t} w_{t} L_{t}=R_{t-1} B_{t-1}+G_{t}+t r_{t-1}+t r_{t}
$$

Notice that the size of each cohort of retirees is one, so that population size does not enter on the right-hand side of the budget constraint. We do not assume that the government is benevolent or maximizes any particular objective function. Instead, our strategy will be to calibrate government behavior in the balanced growth path to U.S. observations, and then explore the consequences of different government policies in reaction to an inflation shock.

In addition to the domestic consumers, we also allow for the possibility that foreigners are investing in the domestic market. Similar to our treatment of the government, the behavior of the foreigners will be taken as exogenous. Later on, the asset holdings of the foreigners will be calibrated to the net nominal position of the rest of the world. The assets held by foreigners in period $t$ will be denoted $a_{F, t}$. In the model economy, net exports are given by interest payments to foreigners minus new foreign investment in domestic assets.

This completes the description of the main elements of our model. In Appendix A, we provide the remaining market-clearing conditions, specify the rental market for houses, and formally define an equilibrium.

\subsection{Calibration}

The model is calibrated to match aggregate statistics of the U.S. economy, as well as key properties of the different groups of households that form the basis of our analysis of financial data in Sections 2 and 3. We therefore calibrate the model under the assumption that there are three different types of consumers, which we will call "the rich," "the middle class," and "the poor." The three groups are distinguished by their earnings profile, their time preference, and by their preference for leisure and bequests. Consistent with our breakdown of the data, a model period lasts ten years, 
with the youngest cohort corresponding to ages up to 35 and the oldest cohort comprising those aged 75 and above.

In order to choose values for household, technology, and government parameters, we select a set of target moments. The parameter values are chosen such that the balanced growth path of our economy matches each of these statistics. In most cases, there is no one-to-one relationship between a moment and a particular model parameter. Nevertheless, it is helpful to distinguish three sets of moments, one for each sector. For households, the preference parameters and households' skill profiles determine the extent of consumption smoothing over time and across the three goods (nondurable consumption, houses, and leisure). We use data on labor earnings, wealth profiles, and aggregate statistics to guide our parameterization. The technology parameters determine the accumulation of tangible and intangible capital in the business sector. Here we target the labor share, the return on capital, and the ratios of depreciation and business capital to GDP. Finally, government behavior is calibrated in order to match the ratios of tax revenues, social security spending, and public debt to GDP.

\section{Preferences and Skill Profiles}

A key requirement for the functional form of the utility function is to be consistent with balanced growth. We therefore choose the following period utility function:

$$
u_{i}\left(c_{t}, d_{t}, 1-l_{t}\right)=\frac{\left(c_{t}^{1-\sigma_{i}}\left(1-l_{t}\right)_{i}^{\sigma}\right)^{1-\gamma}}{1-\gamma}+\eta \frac{d_{t}^{1-\nu_{i}}}{1-\nu_{i}}
$$

and the utility derived from bequests is given by:

$$
v_{i}(b)=\xi_{i} \frac{b^{1-\epsilon_{i}}}{1-\epsilon_{i}}
$$

The Cobb-Douglas specification of preferences over consumption and leisure is standard in the real business cycle (RBC) literature. We also follow the RBC literature in choosing the weight of leisure $\sigma_{i}$ to match average labor supply to a target of 40 percent of the time endowment (in other words, a working adult works an average of 40 hours per week out of a total of 100 "disposable" hours, i.e., excluding sleep and basic maintenance). The parameter is allowed to vary across groups so that we can match labor supply for each group individually. Specifically, if all groups placed the same weight on leisure, the rich group would work too little relative to the data because of their higher 
wealth, which would also lead to widely different labor supply elasticities in the different groups. ${ }^{14}$ The elasticity parameters $\gamma, \nu_{i}$, and $\epsilon_{i}$ govern risk attitudes and the intertemporal elasticity of substitution. We set $\gamma$ to the standard value of $\gamma=2$. Balanced growth then governs the remaining choices, $\nu_{i}=\epsilon_{i}=1-\left(1-\sigma_{i}\right)(1-\gamma)$.

The utility weight $\eta$ determines the expenditure share of durables (which we interpret as houses). To match $\eta$ to data, we take two different targets into account: the ratio of residential capital to physical capital in NIPA (which is 1.44 in 1989), and the ratio of nonfinancial wealth to net worth in the SCF data (58 percent in 1989). The valuation procedures used in these two data sources are not mutually consistent, so we cannot match both statistics at the same time. As an intermediate target that takes account of both numbers, we target a ratio of 1.8 for durables to physical capital, which results in a 36 percent share of durables in net worth.

The parameter $\xi_{i}$ determines the expenditure share of bequests. In the data, bequests are highly concentrated among the richest groups of the population; the vast majority of people do not receive significant bequests at all. For example, Gale and Scholz (1994) reports that only 3.7 percent of households interviewed for the SCF in 1986 had received an inheritance, and households leaving or receiving inheritances had a net worth that is far above average. We therefore assume that only rich people care about bequests, setting $\xi_{p}=\xi_{m}=0$. To calibrate $\xi_{r}$, we follow De Nardi (2004) and target the transfer wealth ratio, which is the fraction of total net worth accounted for by transfers from other households, including bequests and inter-vivos transfers (but not college payments). Using the estimate of Gale and Scholz (1994), we target a transfer wealth ratio of 60 percent.

The time preference parameters $\beta_{i}$ determine the amount of capital accumulation in the economy, the steepness of lifetime asset and consumption profiles, and the relative net worth of different types of households. We therefore use three different targets to set the $\beta_{i}$ : the ratio of the measured capital stock to output in the business sector, which was 1.55 in 1989, the ratio of rich-to-middleclass net worth, which was 12.64 in the 1989 SCF, and the ratio of middle-to-poor net worth, which was 1.94 . To match these targets, we have to assume that the rich type is significantly more patient than the other types. This follows because the rich have a steeper asset profile, and their share of total wealth is much higher than their share of labor earnings. ${ }^{15}$

The skill parameters $\phi_{i, n}$ are chosen such that the cross-section of labor earnings in the balanced

\footnotetext{
${ }^{14}$ In the calibrated model, the Frisch labor supply elasticity at average hours is essentially identical across types, varying from 0.97 for the middle type to 1.00 for the rich type. These elasticities are within the range of existing empirical estimates, see Browning, Hansen, and Heckman (1999). In particular, the values are well below estimates for the elasticity of female and aggregate labor supply, but exceed estimates for males, which is appropriate since the model is formulated at the level of households.

${ }^{15}$ See also Carroll (2000).
} 
growth path of the model matches observed earnings in the 1989 SCF. Notice that because the balanced growth rate is positive, the cross-section of earnings is not identical to the lifetime profile of earnings for a given type. In particular, the lifetime profile is steeper than the cross-section profile, since wages rise over time. Before we can match model earnings to data, a couple of steps are necessary to ensure a consistent measurement of earnings in model and data. In the SCF, we observe labor earnings, business income, and private business wealth and other financial wealth for each type and cohort. The model does not distinguish between private business and other financial assets; business wealth in the data is therefore interpreted as a part of overall financial wealth in the model. Here, however, a potential measurement problem arises. Since in the model there is just one type of financial asset, by definition business wealth has the same rate of return as any other type of financial wealth. In the data, however, we see that the implied returns on private business wealth (the ratio of business income to business wealth) greatly exceeds the return on other financial assets. We deal with this inconsistency by assuming, perhaps realistically, that part of what is labeled as business income in the SCF should actually be interpreted as labor income, since it is derived from running the private business. We therefore construct earnings targets by adding observed labor income and business income that exceeds the income implied by the return on financial assets in the model. This adjustment is important to match the earnings of the rich, who derive a large part of their income from private business. Using $e_{i, n}$ for the SCF earnings of type $i$ and cohort $n, b i_{i, n}$ for business income, $b w_{i, n}$ for business wealth, and $R$ for the rate of return, the earnings targets $\hat{e}_{i, n}$ are:

$$
\hat{e}_{i, n}=e_{i, n}+\left[b i_{i, n}-(R-1) b w_{i, n}\right]
$$

The average level of earnings in the economy is a scale factor. We therefore normalize the skills of the youngest poor cohort to one, and choose the $\phi_{i, n}$ to match the ratio of the earnings of each type and cohort to the earnings of this group. Table 6 displays the (relative) earnings targets.

\section{Technology Parameters}

The only non-standard aspect of our technology is the presence of intangible capital. Since investment in intangible capital is not measured as investment in NIPA, production $Y_{t}$ and measured output are not identical concepts in our economy. To link model output and measured output in the balanced growth path, we use the resource constraint of the economy:

$$
C_{t}+I_{t}^{k}+I_{t}^{h}+G_{t}=Y_{t}-I_{t}^{e}
$$


We equate the right-hand side to the NIPA GDP for the business sector. This output is either consumed or invested in physical (household or business) capital. As mentioned earlier, the ratio of business capital to measured output is matched to data by choosing the time preference parameters of consumers. Given this ratio, the share of intangible capital $1-\rho$ determines the equilibrium rate of return. Given our other calibration choices, we find that setting $\rho=0.5$ leads to a return of 8.25 percent per year, which is close to the 8.4 percent real annual return on the U.S. stock market computed by Jagannathan, McGrattan, and Scherbina (2000) for the period 1945-1999. If we did not allow for intangible capital, the model would imply a much higher, counterfactual return. The share parameter $\alpha$ determines the fraction of output going towards compensation of capital and labor. Once again, we cannot match $\alpha$ to the capital share directly due to the presence of unmeasured output. The measured labor share of our economy is given by $w_{t} L_{t} /\left(Y_{t}-I_{t}^{e}\right)$, which we match to the observed value of 0.66 in the data. The depreciation rate on physical capital can be inferred directly from NIPA. Given the observed NIPA rate for the business sector, we select 7 percent per year, or $\delta_{k}=1-(1-0.07)^{10}$. We also impose that all depreciation rates are identical, so that $\delta=\delta_{e}=\delta_{k}$. Finally, the growth rate $g$ of TFP is set to 2 percent per year, which approximates the average growth rate of the real output per person in the U.S. economy over the past century.

\section{Behavior of the Government and Foreigners}

The government parameters to be calibrated are the labor tax rate $\tau_{t}$, the social security transfer $t r_{t}$, and general government spending $G_{t}$. Given these choices, the interest rate and productivity growth rate pin down the ratio of government debt $B_{t}$ to GDP in the balanced growth path. We choose $\tau$ to match the ratio of tax revenues to measured GDP to its observed value of one-third. The social security transfer $t r_{t}$ is chosen to match the ratio of social security transfers to measured GDP, which is seven percent. Finally, $G_{t}$ is chosen to target the ratio of government debt to GDP. Our target measure of government debt is the net nominal position of the government, as computed in Section 2. ${ }^{16}$

Finally, we need to calibrate the asset holdings of foreigners. Consistent with the calibration to a balanced growth path, we assume that foreign asset holdings grow at the same rate as output. The level of foreign assets is calibrated to the net nominal position of the rest of the world in 1989,

\footnotetext{
${ }^{16}$ An alternative strategy would be to choose $G_{t}$ to target the ratio of (non-social-security) government spending to GDP. However, following this strategy would lead to a counterfactually low ratio of government debt to GDP. The reason for this discrepancy is that the model has just one rate of return, which is targeted to match average stock market returns. Since in the real world government debt has a lower return than equity, we cannot match the government spending ratio and the debt ratio at the same time. For our redistribution exercise, it is important for the model to have a realistic ratio of public debt to private debt, which is why we target the debt-to-GDP ratio.
} 
which is 15.25 percent of measured GDP. The complete model parameterization is summarized in Table 7.

\section{Findings from the Model}

In this section, we combine our empirical results in Sections 2 and 3 with the model described in Section 4 to assess the economic implications of the wealth redistribution triggered by an unanticipated inflation episode. We model the arrival of inflation as a redistribution shock that displaces the economy from its balanced growth path. The direction and amount of the redistribution that we feed into the model is guided by our empirical findings in Section 3. Specifically, Tables 2 and 4 display the gains and losses (relative to GDP) for all sectors, cohorts, and classes given a "Return of the Seventies" inflation shock, under two different scenarios on expectations. We will use our model to assess the reaction of the economy to this redistribution.

\section{The Inflation Experiment}

Suppose that the economy is still on the balanced growth path in period $t$. The new inflation path is then announced at the end of period $t$, and the redistribution takes place at the beginning of period $t+1$. In other words, decisions in period $t$ are not affected by inflation, whereas agents begin period $t+1$ with the asset position after the inflation shock took place. The redistribution is zero sum, and takes place among financial assets saved in period $t$ for period $t+1$. The generations affected by redistribution are all generations alive at the beginning of $t+1$. Formally, we apply the redistribution totals in Tables 2 and 4 (relative to measured GDP) as a change to the beginningof-period assets. ${ }^{17}$ In the household sector, the losses or gains of the cohort up to age 35 affect the initial assets of the cohort 35-44, losses and gains from 35-44 affect initial assets at age 45, and so on. The youngest cohort under 35 starts with zero assets, and therefore does not experience a change in its initial assets. The young rich, however, may receive a different bequest because of the impact on their parents. The level of government debt and net asset holdings of foreigners are changed as well. Since in the model the last cohort dies at age 85 , there is no cohort whose initial assets are affected by the gains and losses of the cohort aged 75-85. For simplicity, we disregard the redistribution occurring in this age group. ${ }^{18}$

\footnotetext{
${ }^{17}$ The redistribution in Table 2 does not add up exactly to zero because of data limitations; in each case, we adjust the gain of the government to ensure a zero-sum redistribution.

${ }^{18}$ To maintain a zero-sum redistribution, we reduce the gain of the government by the amount of losses in this cohort. We have also tried an alternative procedure in which the last cohort is interpreted as "open ended" and receives a larger
} 
Notice that the model does not actually distinguish between the nominal and real assets that give rise to the redistribution effect of inflation in the first place. Since there is no uncertainty in the model, there is no meaningful distinction between nominal and real. If we formally introduced both types of assets, agents would be indifferent between them in any equilibrium, so that any profile of nominal positions could be maintained as an equilibrium outcome. In particular, there would be one equilibrium where the nominal asset positions exactly reproduce the redistribution numbers of Tables 2 and 4, given an unanticipated change in the unit of account of suitable size. However, no further insights would be gained from this formal exercise, as long as the redistribution numbers continue to be based on our empirical findings. ${ }^{19}$

As can be seen from Table 2, the government is a major winner in the redistribution. We thus need to take a stand on how it will adjust its behavior. If tax rates and real government spending do not change, the government budget will be in surplus, and the real value of government debt will decline even further. Alternatively, the government could use the extra revenue to raise government spending or to lower taxes. In our benchmark experiment, the government uses the extra revenue to raise government spending. The real value of government debt returns to its steady-state value, so that we do not induce permanent effects solely by imposing them on the reaction of the government. Alternative government policies will be considered below. We also have to take a stand on the behavior of foreign investors, who also lose from inflation. We treat the foreigners similarly to the government, that is, we assume that the real value of the foreigners' assets returns to the steady state over time. ${ }^{20}$

\section{The Impact on Households}

We begin describing the impact of the inflation shock by looking at individual groups of households, leaving aggregates for later. Our baseline results are for the version of the model without a borrowing constraint. Figure 6 shows the impact on the consumption of each cohort that is alive

total redistribution. The results were very similar to baseline approach. The main difference is a larger decline in the old cohorts' consumption, with little effect on aggregates.

${ }^{19} \mathrm{Of}$ course, it would be a much harder exercise to match the empirical nominal position profiles using a stochastic model with nominal and real assets, in which an inflation shock is expected with some low probability. Constructing such a model is beyond the scope of this paper. Nevertheless, given that, as long as the profiles are matched, the resulting redistribution would be the same, we conjecture that most of the findings from our model would carry over to a more complicated setting. In particular, the post-inflation predictions would be unchanged if after the realization of the shock there were no further uncertainty.

${ }^{20}$ Using other assumptions (such as a permanent reduction in the foreigners' assets) made little difference to the results, mainly because in the 1989 calibration the holdings of foreigners were still relatively low relative to GDP. For both government and foreigners, we assume that 50 percent of the gap to the pre-inflation net nominal position is closed per decade. 
at the time of a Full Surprise inflation shock. Consumption is displayed as a percentage deviation from consumption in the balanced growth path. Each panel shows the reaction of each cohort over their entire life cycle, and periods are labeled by their midpoint. For the cohort $75-85$, for example, the inflation shock hits only in the last period. The graph therefore shows a zero effect until age 70 (that is, the decade 65-74), because for the oldest cohorts those ages are reached before the inflation shock. The middle-class cohorts 35-54 enjoy the largest positive effect, with a gain in consumption of up to six percent relative to the balanced growth path. These cohorts have a relatively large amount of debt (mainly mortgages to finance houses), and inflation lowers the real value of this debt. The pre-retirement cohort of the middle class (up to age 64) and the rich 35-44 also gain, but to a lesser degree. Finally, the youngest cohort of the poor and the middle class are winners as well, albeit for a different reason. These cohorts are not directly affected by redistribution, but they gain from general equilibrium price effects. In particular, a decline in total labor supply leads to a rise in wages.

All other types and cohorts lose from the inflation shock. The young rich lose because they receive a smaller bequest; the others lose because they hold nominal assets that decline in real value. The oldest cohort of the poor takes the largest hit, with a decline in consumption in excess of 12 percent. The old are disadvantaged in two different ways. First, they hold large amounts of nominal assets, which exposes them to inflation. Second, they are at the end of their life cycle, which implies that they cannot smooth the impact on consumption by lowering savings. The impact on consumption of durables or houses (not shown) is very similar to the impact on consumption: once again the young middle class wins, while the old, the rich, and the poor lose relative to the balanced growth path.

Figure 7 shows the impact on labor as a percentage deviation from average labor supply in the balanced growth path. With the exception of retired households, who have lost this margin of adjustment, the losers from inflation compensate for the impact by working more, while the winners (the middle class) enjoy more leisure. Notice that the cohorts with the largest increase in labor supply are the pre-retirement cohorts age 55-64 of the poor and the rich. These households have to use their "last chance" of adjusting, while younger households are able to smooth their adjustment over several decades.

Figure 8 shows the impact on savings. What is striking about this figure is the size of the effects. The middle class 35-44 increase their savings by more than 25 percent of their average savings in the balanced growth path, while the poor 65-74 experience a decline of more than 25 percent. Another interesting observation is that while from age 45 on the reaction of the rich and the poor are quite similar, in the youngest cohort it is the poor and the middle class who behave very similarly. 
The reason is that in the youngest cohort only the rich are directly affected by inflation through receiving a smaller bequest. The poor and the middle class only react to changing prices.

\section{The Impact on Aggregates}

Figure 9 displays the effect on economic aggregates. Here period 0 is the impact period, and effects are displayed for the first five decades after the shock. The change in the interest rate is displayed in basis points, and the effect on the other variables is given as a percentage deviation from the balanced growth path. In each panel, the solid line corresponds to the Full Surprise experiment discussed so far. In absolute terms, aggregates move a lot less than type- and cohort-specific variables, indicating that the individual effects partially offset each other. Nevertheless, a clear pattern emerges, which can be related to the individual characteristics of borrowers and lenders in the economy. The first notable feature is a persistent decline in labor supply. This decline is driven by the middle class, who profit from a positive wealth effect and choose to enjoy more leisure. The decline of labor supply is partially offset by the rich and the poor. The net effect is still negative, however, since a large fraction of the losers from inflation are retirees, who are unable to adjust their labor supply. Therefore, the age structure of gainers and losers from inflation is key for the aggregate effect on labor supply.

The evolution of the capital stock is driven by life-cycle effects as well. The capital stock increases for two decades after the impact of the shock. The relatively young gainers from inflation increase their savings, while the older losers have a smaller decrease in savings, since they are closer to the end of the life cycle. The capital stock continues to increase over the first decades, because the losers reach the end of their life cycle before the gainers do. The middle-class gainers from inflation are still alive after twenty years, and their additional savings account for the high capital stock in this period. The effect is reversed when the middle class cohorts who initially had the largest gains reach the end of their life cycle. After a number of decades, none of the cohorts that were directly affected by the inflation shock remain, and the aggregate effects begin to peter out.

The net impact on output is a decline of up to 0.8 percent relative to the balanced growth path during the first three decades, and an increase of up to 0.25 percent thereafter. Notice that while the effects are moderate in magnitude, they are extremely persistent. Given an average decline of about 0.6 percent relative to the balanced growth path over the first twenty years, the cumulative amount of output lost is large. In addition, the output effect is on the same order of magnitude as what is generated by representative-agent models with monetary frictions. For example, Cooley and Hansen (1989) find that in a standard cash-in-advance model with stochastic money supply, 
a permanent increase in inflation from 0 to 10 percent reduces steady-state output by about 0.8 percent (with a cash-in-advance constraint that requires that the equivalent of one month of consumption has to be held in cash). Notice that we consider a smaller experiment (a one-decade-long shock that adds an average of 5 percent inflation per year), and our effects arise from redistribution only.

So far, we have only considered the Full Surprise inflation experiment. Under the alternative Indexing ASAP assumption, assets and liabilities with maturities below ten years are affected less by inflation, since nominal interest rates are assumed to adjust to the new expected inflation path right away. As Table 2 shows, under this assumption the net loss of the household sector is only 3.1 percent of GDP, instead of 8.1 percent under the Full Surprise assumption. Despite the lower total amount of redistribution, the economic effects of an Indexing ASAP inflation shock are not just a scaled-down version of the Full Surprise shock. The reason is that the maturity structure of assets and liabilities differs across sectors and groups of households.

In Figure 9, the effects of the Indexing ASAP experiment are given by the dotted lines. The responses still have a similar shape, but are generally smaller. The initial impact on output declines to 0.25 percent, but it is more persistent than in the Full Surprise case. Additional insights can be gained if we decompose the overall redistribution experiment into two components: redistribution among households, and redistribution among the household sector as a whole and the government and foreigners. Figure 9 shows what happens in the Full Surprise experiment if we only redistribute among households in the same amount as before, but isolate the government and foreigners from the redistribution. In terms of labor supply and output, this households-only redistribution leads to an even larger labor supply and output effect. The reason is that if the government receives its windfall, the households are poorer, while the demand for government consumption increases. Both effects increase labor supply. Turning to capital, results are changed only by a small degree under the households-only redistribution. This is different under the Indexing ASAP assumption, where in the households-only experiment the capital stock increases (relative to full redistribution). The reason for this discrepancy is related to the maturity structure of nominal assets in the different sectors. Most short-term borrowing and lending takes place within the household sector, while the government has a large amount of long-term debt. In the Indexing ASAP scenario, where redistribution affects mostly long-term nominal assets, the windfall of the government is a much larger component of overall redistribution than in the Full Surprise scenario. From the perspective of the households, the government's windfall is a loss of wealth, which tends to depress savings. Consequently, removing this loss has a large impact in the Indexing ASAP scenario. In contrast, in the Full Surprise scenario results are mostly driven by the life-cycle effects of redistribution within the 
household sector.

We repeated both experiments in versions of the model with a binding borrowing constraint, i.e., consumers can only borrow up to fraction $\psi$ of the value of their houses. We experimented with a variety of values for $\psi$, but found that in each case the results were virtually the same as in the model without financial constraints. Intuitively, a borrowing constraint will change the reaction of households who are right at the constraint when the inflation shock hits. Since these households are borrowers, they gain from inflation; that is, the real value of their debt declines. Compared to an unconstrained household, a constrained household will spend a larger fraction of the windfall on additional consumption in the impact period, since consumption was previously limited by the constraint. At the same time, there will also be a larger increase in leisure, since a constrained household tends to increase labor supply to overcome the restriction. Quantitatively, however, these effects turn out to be small. The reason is that only the youngest households are financially constrained, and these households account for only a small part of the overall effects.

\section{Alternative Government Policies}

The purpose of our model is to gauge how the economy reacts to the redistribution of wealth induced by an inflation episode. While the model makes precise predictions about the reaction of the household sector, we had to make assumptions about the reaction of the government, which is a major beneficiary of the inflation-induced redistribution. The question arises whether our results are sensitive to alternative assumptions about the government's reaction to the inflation windfall. To evaluate the role of the government, we computed outcomes under a variety of scenarios concerning the reaction of the government.

In our model, apart from increasing government spending, the government may put additional funds to two alternative uses: it could lower taxes, or it could increase social security spending. The top panel in Figure 10 compares the impact on output across the three possible "pure" policies, i.e., the entire windfall is used either to increase general spending, increase social security, or lower income taxes. In each case, we use the Full Surprise scenario; effects are qualitatively similar, but smaller, in the Indexing ASAP case. We maintain the assumption that real government debt returns to its original steady state. The shape of the impact on aggregate output is remarkably similar across the three policies. In each case, output initially declines due to the negative effect on labor supply, and later increases due to the increased capital stock. Throughout the entire transition, output is highest if taxes are lowered, and lowest if pensions are increased. The intuition is that 
lowering taxes lowers distortions at the labor-leisure margin, which increases output. Subsidizing pensioners, in contrast, lowers incentives for saving.

So far, we have taken as given that the effect of wealth redistribution on the government is transitory, i.e., real government debt returns to its original steady state. However, the government could also decide to permanently keep government debt at its lower post-inflation value, which would allow either a permanent increase in spending or a permanent decrease in taxes. The bottom panel of Figure 10 displays the output effect of the three possible reactions in this scenario. Since the economy now converges to a different balanced growth path, permanent effects on output arise. Lowering taxes leads to the largest increase-about two percent of output in the steady state. Thus, in the long run, lowering taxes increases output more than increasing government spending. Raising pensions has almost no long-run effect. Since pensions are paid late in life, in this case the lower government debt is counteracted by lower private saving.

\section{Welfare Implications}

While the redistribution numbers computed in Section 3 give us a good indication of who gains and who loses from inflation, they are not sufficient to determine the overall welfare effect on each group. Households are also affected by the reaction of the government to inflation, as well as by general equilibrium price changes. To gauge the impact of inflation on group-specific welfare, Table 8 compares the utility of each type and cohort of consumer alive in the impact period to balanced-growth utility in the Full Surprise scenario under the three possible government policies, with government debt returning to steady state. Table 9 provides the same information for the $I n$ dexing ASAP case. For ease of interpretation, the numbers are expressed as equivalent proportional variations in consumption (both nondurable and durable). For example, an entry of -1.00 would indicate that the utility of the household in the inflation scenario is equivalent to the utility gained from the balanced growth allocation, with consumption and housing scaled down by one percent until the end of the life cycle. For people from the poor and middle groups who have reached the final period of their life, the welfare number is exactly equal to their percentage change in consumption. For younger people, this is not the case, because they can also adjust leisure, and the old rich can adjust bequests. We also display a weighted welfare criterion that places equal weight on each group alive in the impact period. ${ }^{21}$ We discuss the results for the Full Surprise case first;

\footnotetext{
${ }^{21}$ While a formal political economy analysis is beyond the scope of this paper, our individual and aggregate welfare measures correspond to the objective functions of two commonly used political economy models, and in this sense indicate the "political popularity" of inflation. Under majority voting, each voter picks the platform which yields higher utility. In this case, each group's political preferences can be read off the sign of the group-specific welfare
} 
qualitatively, the results under the Indexing ASAP assumption are similar.

The welfare calculations show that government policy determines the direction of the welfare effect for a number of groups of households. In the baseline experiment with an adjustment in government expenditure, a majority of households lose from inflation. Specifically, for all but one of the groups the sign of the welfare change is equal to the sign of the direct redistribution effect in Table 3 . The exception consists of the young and poor households, whose small direct loss is more than offset by wage increases, which are driven by the reduction in aggregate labor supply. The middle class aged 35-45 gains most from inflation with a positive effect slightly above 11 percent relative to the balanced growth path, while the oldest cohort of the poor suffers the largest welfare loss of over 12 percent. In this scenario, there is a direct link between redistribution and welfare, because the government uses its windfall to increase government spending, which does not enter anybody's utility.

The situation is different, however, if the government rebates its windfall to the households. In particular, if government spending is adjusted through increasing pensions, a majority of households gain from the redistribution shock, including most of the poor. The oldest group among the poor, which suffers a 12 percent welfare loss if the adjustment is through government spending, now experiences a gain of 0.3 percent. For a number of groups (including this one) the direct loss through the revaluation of their assets is more than offset by the compensating higher pension payments. Thus, while the poor as a group experience a negative direct redistribution effect, this loss turns out to be easy to compensate, precisely because it does not take much in terms of transfers to improve the well-being of the poor. From a political economy perspective, we conclude that the government can adopt simple fiscal policies in reaction to an inflation shock which imply that the shock benefits a majority. Thus, policymakers may be tempted to inflate the economy not just because they take some direct interest in the fiscal position of the government, but also because such a policy may actually have wide support if the losers from inflation receive some compensation. ${ }^{22}$

The temptation of inflation becomes even more apparent when we consider the weighted welfare measure, which is positive in each case. Three effects are at work here. First, the economy as

effect. Probabilistic voting (see Persson and Tabellini 2000) introduces noise to voting decisions, and it can be shown that voting outcomes are equivalent to maximizing a weighted welfare function of the same type as our aggregate welfare measure.

${ }^{22}$ It is intriguing to observe that the U.S. inflation episode in the 1970s started right after social security was first indexed to inflation in 1972. While this policy change is unlikely to have been the main cause of the episode, it certainly lowered the political cost of inflation, and therefore may help explain why it took a decade until inflation was brought under control. In fact, the formula for the cost-of-living adjustment of social security was originally specified incorrectly. The retirees were actually overcompensated for inflation until 1978 (see Duggan, Gillingham, and Greenlees 1996), so real pensions rose as a result of inflation, just as in our "Pensions Adjust" policy experiment. 
a whole experiences a net gain, because inflation deflates the wealth of foreigners. Second, a reduction in government debt also registers as a welfare gain, since Ricardian equivalence does not hold in our OLG-economy with distortionary taxation. Third, inflation redistributes wealth from the rich to the middle class and to some of the poor. Since the rich have the lowest marginal utility, this redistribution also has a positive impact on the weighted welfare measure.

We can gauge the relative importance of the taxation of foreigners by computing results for an otherwise identical experiment that leaves the real value of the foreign asset holdings intact. In other words, redistribution takes place only between domestic households and the government, while the rest of the world is protected from inflation. To balance the total redistribution, we assign a smaller gain to the government. In this scenario, the overall welfare effect remains positive, but is smaller. In the Full Surprise case with government debt returning to the steady state, the weighted welfare effects are 0.17 if government spending adjusts, 0.99 when taxes adjust, and 0.98 when pensions are raised. In the spending experiment, the exclusion of foreign debt has almost no effect on welfare. The reason is that neither government spending nor the consumption of foreigners enter utility, so that the taxation of foreigners makes little difference to the domestic households if the government consumes all the gains. In the tax and pensions experiments, the implicit taxation of foreigners contributes slightly more than 50 percent of the overall welfare effect. The welfare effect is also positive if neither foreigners nor the government are affected by inflation, i.e., if we consider redistribution among consumers only. Here the welfare numbers are the same as the ones we got previously under the assumption that government spending adjusts.

The welfare effects are similar if we work under the alternative assumption that government debt does not return to the steady state. Even though we saw that making permanent changes to debt and taxes can have a sizable effect on output in the balanced growth path, this is of little relevance to the initial generations. The results are also qualitatively unchanged if we consider the Indexing $A S A P$ scenario. Individual welfare effects are generally smaller due to the reduced redistribution volume, but duration effects are important. For the poor, for example, losses are much smaller under the Indexing ASAP scenario relative to Full Surprise, since most of their nominal assets are short term. For the rich as well as for the government and foreigners, the difference between the two scenarios is smaller. Once again, the weighted welfare effect is positive in each scenario.

When interpreting these results, one has to keep in mind that our model isolates only the welfare implications of the redistribution effect of an inflation shock. The traditional literature on the welfare cost of inflation, in contrast, builds on monetary frictions (from which we abstract), and finds that inflation lowers welfare. At the same time, the size of the effects is generally shown to be small, so that the positive effects arising from redistribution that we document here are likely 
to dominate. To give a concrete example, the estimates by Lucas (2000) imply that a permanent rise in inflation from zero to five percent lowers welfare in steady state by the equivalent of about 0.5 percent of consumption. The inflation shock that underlies our experiments is smaller, since it is transitory: inflation increases by about five percent over a single ten-year period. Even so, as long as the government's windfall is not used to increase government spending (which does not enter utility), in every scenario the positive welfare effect arising from redistribution is at least twice as large in absolute value as Lucas' welfare cost estimate. In the Full Surprise scenario, the positive welfare effect exceeds two percent for both the tax rebate and pension policies. Thus, even when we take into account standard estimates of the welfare cost of inflation arising from monetary frictions, the conclusion remains that under suitable government policies, the overall welfare effect of an unanticipated inflation shock is positive and large.

\section{Results for Baseline Year 2001}

We saw in Section 2 that there have been substantial changes in the net nominal positions of different sectors of the U.S. economy over the last 15 years. Most importantly, there has been a large decline in the net nominal position of the household sector, and a corresponding increase in the position of the rest of the world. We repeated our experiment with redistribution numbers generated from data in 2001 to gauge how important these changes are for the effects of inflation. To make results comparable, we used the same model calibration as before (apart from the asset positions of the rest of the world and the government, which were adjusted to their 2001 values).

Figure 11 shows the impact on economic aggregates for the 2001 experiment. Qualitatively and quantitatively, the effects are very similar to 1989 results. Important differences do arise, however, when we consider the welfare implications. The weighted welfare measures now show a bigger positive effect of up to 3.13 percent in the Full Surprise scenario with an adjustment in taxes (0.33 if spending adjusts, and 3.04 with an adjustment in pensions. The numbers for the gradual experiment are $0.21,1.62$, and 1.53 in the spending, taxes, and pension scenarios). The main reason for this larger effect is the increased net nominal position of the rest of the world. The devaluation of assets owned by foreigners is a windfall from the perspective of domestic households. The importance of foreigners can be gauged by recomputing the experiment under the assumption that foreigners are isolated from inflation (as if, counterfactually, foreigners only held inflation-indexed bonds). The weighted welfare effects in the spending, tax, and pension experiments are $0.21,0.47$, and 0.45 percent in the Indexing ASAP scenario, and 0.33, 0.52, and 0.52 percent in the Full Surprise scenario. Thus, under the assumption that the government uses its windfall to either rebate taxes or 
raise pensions, the inflation tax on foreigners accounts for between 70 and 85 percent of the overall welfare effects.

In summary, across all our experiments we find that inflation-induced redistribution has a positive effect on standard weighted welfare measures. Even if we abstract from the fact that foreigners hold a sizable amount of domestic nominal assets, these positive effects are large enough to outweigh standard estimates of the welfare cost of inflation arising from monetary frictions. The large recent increase in foreigners' holdings of domestic, dollar-denominated debt, however, has made inflation an even more attractive proposition from a U.S. perspective. In effect, foreigners are currently lending large amounts of funds to the U.S. at terms of repayment that are under control of the U.S. Federal Reserve System. Even moderate taxation of these funds through an increase in inflation of about 5 percent per year would result in substantial welfare gains for U.S. households. ${ }^{23}$

\section{Conclusions}

The goal of this paper was to examine the importance of wealth redistribution as a channel for real effects of inflation. We have documented the distribution of nominal assets and liabilities in the U.S. economy, and we have used those numbers to compute the wealth redistribution that would be induced by a moderate inflation episode such as the 1970s. We find that even moderate inflation leads to sizeable redistribution of wealth. The wealth effects of inflation induce highly persistent effects on both individual welfare and aggregate economic activity. The main source of aggregate effects is that borrowers are younger than lenders. Standard life cycle considerations imply that the responses of young winners and old losers are not offsetting.

Discussion of optimal monetary policy in the U.S. is often based on models with monetary frictions, where inflation causes inefficiencies and therefore lowers welfare. Our model abstracts from frictions to isolate the distributional effects of inflation. Based on U.S. data, we show that the redistribution caused by an inflation episode tends to increase the welfare of domestic households on average. This conclusion arises for two reasons. First, inflation imposes a tax on foreigners who

\footnotetext{
${ }^{23}$ While these findings depend on the specific distribution of nominal assets and liabilities that we documented for the U.S., there is evidence to suggest that similar features may have played a role in other historical inflation episodes. For example, concerning the German hyperinflation of 1923, Holtfrerich (1986) finds that the distribution of wealth was leveled, with the rich losing the most and the gains being concentrated in the middle class. Moreover, "a significant proportion of creditor's losses arising out of the inflation was borne by foreigners who had taken up creditor positions in marks. The losses these suffered were of at least the same order of magnitude as German Reparation Payments between 1919 and 1923." (p. 333). Thus, despite the severe economic disruption caused by the hyperinflation, the distributional impact may have been among the key factors that rendered inflation attractive.
} 
hold domestic nominal assets. If the foreign net nominal position is positive, inflation creates a windfall from the perspective of domestic households. Second, inflation tends to redistribute income from the relatively rich to the relatively poor, which is also registered as an improvement by standard weighted welfare measures.

Our findings therefore lead to some doubts regarding the conventional wisdom that low inflation is always in the best interest of the domestic population. There is a sizable fraction of the U.S. population which would stand to gain if another inflation episode such as the one in the 1970s were to occur. As more and more nominal assets are held by foreigners, this fraction of the population continues to grow. Currently, the potential welfare gains from taxing foreigners' nominal assets through a moderate increase in inflation easily outweigh standard estimates of the welfare cost of inflation. The current widespread optimism regarding continued low inflation in the foreseeable future may be misplaced.

We do not mean to suggest that policymakers should use inflation systematically to achieve distributional purposes. Clearly, a systematic policy of this kind would be impossible to implement, since redistribution arises only to the extent that inflation is unanticipated. At the same time, if the potential gains from inflation through redistribution are large, policymakers may find it more difficult to resist the temptation of inflation. Being aware of the potential redistribution effect may be important even if controlling inflation is the ultimate aim.

To this end, our analysis may provide a useful starting point for future research into the political economy of inflation. One of our key findings is that the cohort welfare effects are highly sensitive with respect to the fiscal policy regime followed by the government. If the government simply raises general spending, only the young middle class experiences a net gain from inflation, so that inflation would not be widely popular. If the windfall is used to raise pensions, however, the poor as well as the old middle class are compensated for all their losses, and most groups, apart from the very rich, stand to gain from inflation. As we discuss above, during the 1970s the U.S. did have a policy of compensating retirees, since social security pensions were (perhaps inadvertently) over-indexed to inflation starting in 1972. Our results suggest that this policy may have contributed to the political sustainability of inflation. In future research, we plan to explore the role of fiscal policies and redistribution effects in other historical inflation episodes. 


\section{A Definition of an Equilibrium}

It simplifies notation to define aggregate consumption, domestic assets, investment, and net exports in the economy:

$$
\begin{aligned}
C_{t} & =\sum_{i} \mu_{i} \sum_{s=t-N}^{t} c_{i, s, t}, \\
A_{t} & =\sum_{i} \mu_{i} \sum_{s=t-N}^{t} a_{i, s, t}, \\
I_{t}^{h} & =\sum_{i} \mu_{i} \sum_{s=t-N}^{t}\left[d_{i, s, t}-(1-\delta) d_{i, s-1, t-1}\right], \\
I_{t}^{k} & =K_{t+1}-\left(1-\delta_{k}\right) K_{t}, \\
I_{t}^{e} & =E_{t+1}-\left(1-\delta_{k}\right) E_{t}, \\
N X_{t} & =R_{t} a_{F, t}-a_{F, t+1} .
\end{aligned}
$$

where $\mu_{i}$ is the size of group $i$, and we have $\sum_{i} \mu_{i}=1$. For the definition of an equilibrium, we also have to be more specific about the rental price of houses, and the amount of assets committed to housing the old. The houses rented by the old people are part of the stock of assets owned by other households. The rental price of houses adjusts such that the return to investing in houses for rent is equal to the interest rate. If the rent is $p_{t}$ per unit, investing in one house requires $1-p_{t}$ per unit today for a return of $1-\delta$ tomorrow. The returns are therefore equalized if:

$$
\frac{1-\delta}{1-p_{t}}=R_{t+1}
$$

or:

$$
p_{t}=1-\frac{1-\delta}{R_{t+1}} .
$$

The amount of assets committed to housing the old is given by:

$$
D_{t}=\left(1-p_{t}\right) \sum_{i} \mu_{i} d_{i, t-N, t}=\frac{1-\delta}{R_{t+1}} \sum_{i} \mu_{i} d_{i, t-N, t} .
$$

Definition 1 (Equilibrium) An equilibrium consists of a sequence of prices $\left\{w_{t}, R_{t}, p_{t}\right\}$, household allocations $\left\{c_{i, s, t}, d_{i, s, t}, a_{i, s, t}, l_{i, s, t}, b_{i, s}\right\}$, foreigners' assets $\left\{a_{F, t}\right\}$, firm decisions $\left\{Y_{t}, K_{t}, E_{t}, L_{t}\right\}$, and government decisions $\left\{B_{t}, \tau_{t}, G_{t}, t_{t}\right\}$ such that:

1. Given prices, the households' decisions maximize utility (1) subject to the budget constraints (2)-(5) and the borrowing constraint (6).

2. Given prices, firms maximize profits, i.e., (7) is satisfied. 
3. The government budget constraint (8) is satisfied in every period.

4. The rental market clears, i.e., (9) holds.

5. The goods market clears in every period:

$$
C_{t}+I_{t}^{k}+I_{t}^{e}+I_{t}^{h}+G_{t}+N X_{t}=Y_{t}
$$

6. The labor market clears in every period:

$$
L_{t}=\sum_{i} \sum_{s=t-N}^{t} \phi_{i, t-s} l_{i, s, t} .
$$

7. The asset market clears in every period:

$$
A_{t}+a_{F, t}=K_{t}+E_{t}+D_{t}+B_{t}
$$




\section{References}

Aiyagari, S. Rao. 1994. "Uninsured Idiosyncratic Risk and Aggregate Saving." Quarterly Journal of Economics 109 (3): 659-84.

Albanesi, Stefania. 2002. "Inflation and Inequality." Unpublished Manuscript, Bocconi University.

Bohn, Henning. 1988. "Why Do We Have Nominal Government Debt?" Journal of Monetary Economics 21 (1): 127-40.

- 1990a. "A Positive Theory of Foreign Currency Debt." Journal of International Economics 29 (3-4): 273-92.

. 1990b. "Tax Smoothing with Financial Instruments." American Economic Review 80 (5): 1217-30.

- 1991. "Time Consistency of Monetary Policy in the Open Economy." Journal of International Economics 30 (3-4): 249-66.

Browning, Martin, Lars P. Hansen, and James J. Heckman. 1999. "Micro Data and General Equilibrium Models." Chapter 8 of Handbook of Macroeconomics Volume 1A, edited by John B. Taylor and Michael Woodford. Amsterdam: Elsevier.

Budría Rodríguez, S., J. Díaz-Gimenéz, V. Quadrini, and J.V. Ríos-Rull. 2002. "Updated Facts on the U.S. Distributions of Earnings, Income, and Wealth." Federal Reserve Bank of Minneapolis Quarterly Review 26 (3): 2-34.

Burnside, Craig, Martin Eichenbaum, and Sergio Rebelo. 2003. "Government Finance in the Wake of Currency Crises." National Bureau of Economic Research Working Paper 9786.

Carroll, Christopher D. 2000. "Why Do the Rich Save So Much?” In Does Atlas Shrug? The Economic Consequences of Taxing the Rich, edited by Joel B. Slemrod, 465-84. Cambridge: Harvard University Press.

Castañeda, Ana, Javier Díaz-Gimenéz, and José-Víctor Ríos-Rull. 2003. "Accounting for the U.S. Earnings and Wealth Inequality." Journal of Political Economy 111 (4): 818-57.

Cooley, Thomas F. and Gary D. Hansen. 1989. "The Inflation Tax in a Real Business Cycle Model." American Economic Review 79 (4): 733-48.

De Nardi, Mariacristina. 2004. "Wealth Inequality and Intergenerational Links." Review of Economic Studies 71 (3): 743-68.

Doepke, Matthias and Martin Schneider. 2004. "Real Effects of Inflation through the Redistribution of Nominal Wealth: Technical Appendix." Unpublished Manuscript, UCLA and NYU.

Duggan, James E., Robert Gillingham, and John S. Greenlees. 1996. "Distributional Effects of Social Security: The Notch Issue Revisited." Public Finance Quarterly 24 (3): 349-70.

Erosa, Andrés and Gustavo Ventura. 2002. "On Inflation as a Regressive Consumption Tax." Journal of Monetary Economics 49 (4): 761-95. 
Fernández-Villaverde, Jesús and Dirk Krueger. 2001. "Consumption and Saving over the Life Cycle: How Important are Consumer Durables?" Unpublished Manuscript, University of Pennsylvania.

Fisher, Irving. 1933. “The Debt-Deflation Theory of Great Depressions.” Econometrica 1 (4): 337-357.

Gale, William G. and John Karl Scholz. 1994. "Intergenerational Transfers and the Accumulation of Wealth.” Journal of Economic Perspectives 8 (4): 145-60.

Hall, Robert E. 2001. "The Stock Market and Capital Accumulation." American Economic Review 91 (5): 1185-202.

Holtfrerich, Carl-Ludwig. 1986. The German Inflation 1914-1923: Causes and Effects in International Perspective. New York: Walter de Gruyter.

Hubbard, R. Glenn, Jonathan Skinner, and Stephen P. Zeldes. 1995. "Precautionary Saving and Social Insurance.” Journal of Political Economy 103 (2): 360-99.

Huggett, Mark. 1996. "Wealth Distribution in Life-Cycle Economies." Journal of Monetary Economics 38 (3): 469-94.

Jagannathan, Ravi, Ellen R. McGrattan, and Anna Scherbina. 2000. "The Declining U.S. Equity Premium.” Federal Reserve Bank of Minneapolis Quarterly Review 24 (4): 3-19.

Krusell, Per and Anthony A. Smith, Jr. 1998. "Income and Wealth Heterogeneity in the Macroeconomy." Journal of Political Economy 106 (5): 867-896.

Laitner, John. 2001. "Secular Changes in Wealth Inequality and Inheritance." Economic Journal 111 (474): 691-721.

Lucas, Robert E., Jr. 2000. "Inflation and Welfare.” Econometrica 68 (2): 247-74.

McGrattan, Ellen R. and Edward C. Prescott. 2004. "Taxes, Regulations, and the Value of U.S. and U.K. Corporations.” Federal Reserve Bank of Minneapolis Staff Report 309.

Persson, Torsten and Guido E. Tabellini. 2000. Political Economics: Explaining Economic Policy. Cambridge, Massachusetts: MIT Press.

Persson, Mats, Torsten Persson, and Lars E. O. Svensson. 1998. "Debt, Cash Flow and Inflation Incentives: A Swedish Example." In The Debt Burden and Its Consequences for Monetary Policy, edited by Guillermo Calvo and Mervyn King, 28-62. New York: St. Martin's Press.

Quadrini, Vincenzo. 2000. "Entrepreneurship, Saving and Social Mobility." Review of Economic Dynamics 3 (1): 1-40. 


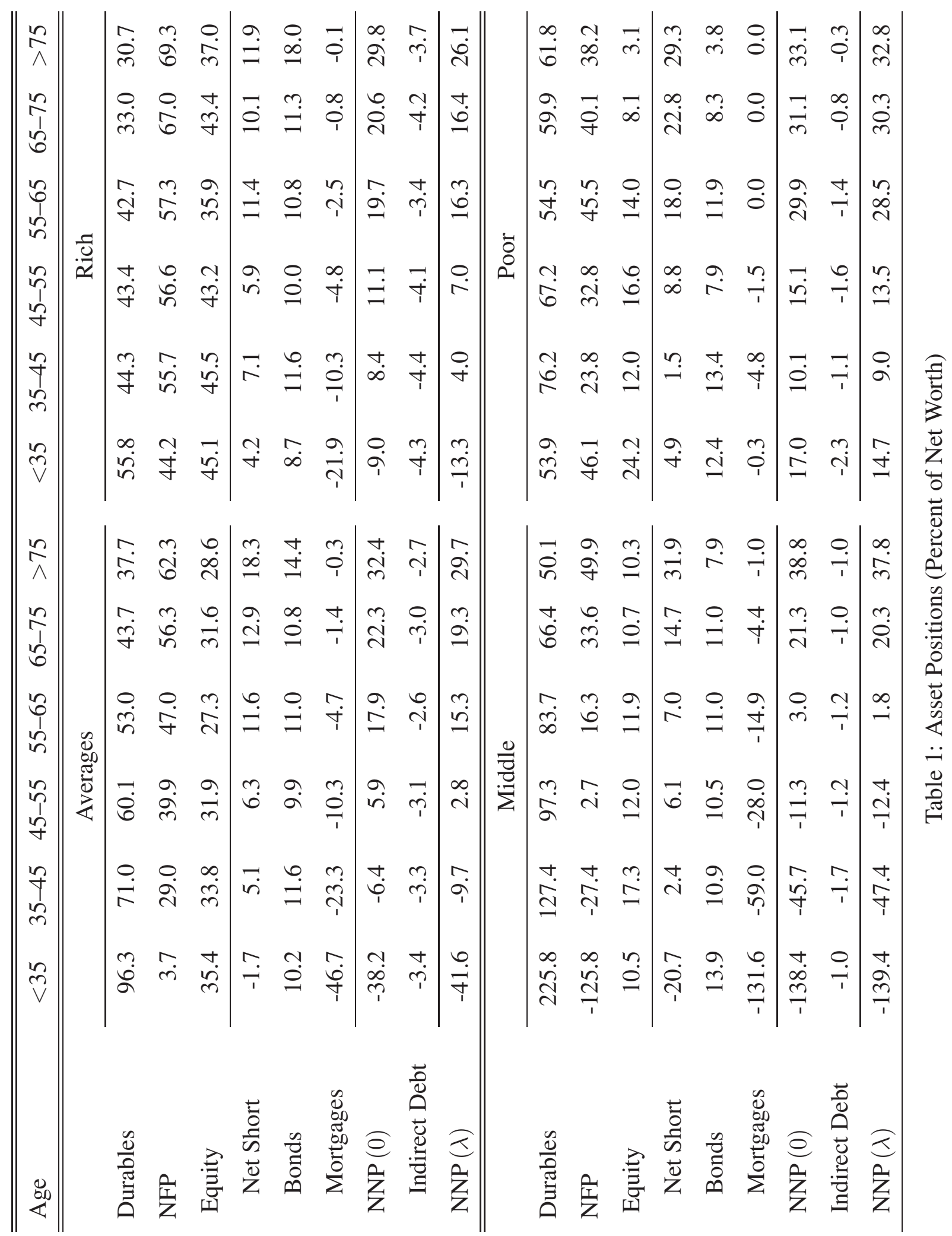




\begin{tabular}{|c|c|c|c|c|c|c|c|c|c|c|}
\hline \multirow[b]{3}{*}{1989} & \multirow{2}{*}{\multicolumn{2}{|c|}{ Government }} & \multirow{2}{*}{\multicolumn{2}{|c|}{ Rest of World }} & \multicolumn{6}{|c|}{ Households } \\
\hline & & & & & \multicolumn{2}{|c|}{ Total } & \multicolumn{2}{|c|}{ Losses } & \multicolumn{2}{|c|}{ Gains } \\
\hline & +14.1 & +5.2 & -6.7 & -2.3 & -8.1 & -3.1 & -17.5 & -6.6 & +9.4 & +3.5 \\
\hline 2001 & +15.9 & +6.7 & -13.4 & -5.8 & -3.4 & -1.9 & -12.0 & -6.0 & +8.6 & +4.1 \\
\hline
\end{tabular}

Net Gain from Full Surprise and Indexing ASAP Experiments.

Table 2: Redistribution across Sectors, 1989 and 2001, in Percent of GDP

\begin{tabular}{lrrrrrr}
\hline \hline Age & \multicolumn{2}{c}{ Poor } & \multicolumn{2}{c}{ Middle } & \multicolumn{3}{c}{ Rich } \\
\hline$<35$ & $\mathbf{- 6 . 4}$ & -0.3 & $\mathbf{+ 6 0 . 9}$ & +22.2 & $\mathbf{+ 5 . 8}$ & +1.5 \\
$35-45$ & $\mathbf{- 3 . 9}$ & -2.1 & $\mathbf{+ 2 0 . 7}$ & +8.7 & $\mathbf{- 1 . 7}$ & -1.4 \\
$45-55$ & $\mathbf{- 5 . 9}$ & -1.7 & $\mathbf{+ 5 . 5}$ & +2.2 & $\mathbf{- 3 . 1}$ & -2.2 \\
$55-65$ & $\mathbf{- 1 2 . 5}$ & -2.9 & $\mathbf{- 0 . 8}$ & -0.1 & $\mathbf{- 7 . 1}$ & -2.7 \\
$65-75$ & $\mathbf{- 1 3 . 3}$ & -2.0 & $\mathbf{- 8 . 9}$ & -2.5 & $\mathbf{- 7 . 2}$ & -3.3 \\
$>75$ & $\mathbf{- 1 4 . 3}$ & -1.0 & $\mathbf{- 1 6 . 5}$ & -2.0 & $\mathbf{- 1 1 . 4}$ & -4.7 \\
\hline
\end{tabular}

Net Gain from Full Surprise and Indexing ASAP Experiments.

Table 3: Redistribution in 1989, in Percent of Net Worth

\begin{tabular}{|c|c|c|c|c|c|c|c|c|}
\hline \multirow[b]{2}{*}{ Age } & \multicolumn{2}{|c|}{ All } & \multicolumn{2}{|c|}{ Poor } & \multicolumn{2}{|c|}{ Middle } & \multicolumn{2}{|c|}{ Rich } \\
\hline & -47 & -49 & -22 & -14 & +32 & +41 & -57 & -76 \\
\hline$<35$ & +27 & +24 & -1 & -1 & +22 & +21 & +6 & +4 \\
\hline $35-45$ & +14 & +12 & -2 & -2 & +20 & +22 & -4 & -8 \\
\hline $45-55$ & -5 & -12 & -3 & -2 & +6 & +6 & -8 & -16 \\
\hline $55-65$ & -28 & -24 & -8 & -5 & -1 & 0 & -19 & -19 \\
\hline $65-75$ & -30 & -29 & -7 & -3 & -6 & -5 & -17 & -21 \\
\hline$>75$ & -25 & -20 & -1 & -1 & -9 & -3 & -15 & -16 \\
\hline
\end{tabular}

Net Gain from Full Surprise and Indexing ASAP Experiments.

Table 4: Redistribution in 1989, Group Totals, in Percent of Total Loss of Household Sector 


\begin{tabular}{lrrrrrr}
\hline \hline Age & \multicolumn{2}{c}{ Poor } & \multicolumn{2}{c}{ Middle } & \multicolumn{3}{c}{ Rich } \\
\hline$<35$ & $\mathbf{- 7 . 1}$ & -4.0 & $\mathbf{+ 1 0 1 . 7}$ & +54.1 & $\mathbf{+ 2 . 5}$ & +2.4 \\
$35-45$ & $\mathbf{- 4 . 1}$ & -2.5 & $\mathbf{+ 2 7 . 8}$ & +15.1 & $\mathbf{+ 1 . 0}$ & +0.4 \\
$45-55$ & $\mathbf{- 6 . 2}$ & -2.9 & $\mathbf{+ 9 . 0}$ & +1.9 & $\mathbf{- 1 . 4}$ & -1.4 \\
$55-65$ & $\mathbf{- 9 . 6}$ & -3.7 & $\mathbf{+ 2 . 1}$ & -1.1 & $\mathbf{- 5 . 4}$ & -2.9 \\
$65-75$ & $\mathbf{- 1 2 . 4}$ & -3.6 & $\mathbf{- 0 . 1}$ & -1.0 & $\mathbf{- 6 . 4}$ & -3.2 \\
$>75$ & $\mathbf{- 1 1 . 8}$ & -1.6 & $\mathbf{- 1 0 . 5}$ & -2.5 & $\mathbf{- 7 . 1}$ & -3.4 \\
\hline
\end{tabular}

Net Gain from Full Surprise and Indexing ASAP Experiments.

Table 5: Redistribution in 2001, in Percent of Net Worth

\begin{tabular}{lcccc}
\hline \hline & $<35$ & $35-45$ & $45-55$ & $55-65$ \\
\hline Rich & 3.41 & 7.07 & 5.80 & 4.25 \\
Middle Class & 2.34 & 3.42 & 3.65 & 2.00 \\
Poor & 1.00 & 1.91 & 1.72 & 0.87 \\
\hline
\end{tabular}

Table 6: Relative Earnings Targets

\begin{tabular}{|c|c|c|c|c|c|}
\hline Preferences & & Skills & & Technology & Government \\
\hline$\gamma=2$ & $\phi_{r, 0}=2.59$ & $\phi_{m, 0}=2.39$ & $\phi_{p, 0}=1.03$ & $\alpha=0.41$ & $\tau=0.5$ \\
\hline$\sigma_{r}=0.66$ & $\phi_{r, 1}=5.15$ & $\phi_{m, 1}=2.96$ & $\phi_{p, 1}=1.52$ & $\rho=0.5$ & $t r=0.03$ \\
\hline$\sigma_{m}=0.71$ & $\phi_{r, 2}=6.13$ & $\phi_{m, 2}=3.11$ & $\phi_{p, 2}=1.49$ & $\delta=0.52$ & $G / Y=0.24$ \\
\hline$\sigma_{p}=0.70$ & $\phi_{r, 3}=8.10$ & $\phi_{m, 3}=2.35$ & $\phi_{p, 3}=1.13$ & $\delta_{K}=0.52$ & \\
\hline$\eta=0.23$ & $\phi_{r, 4}=0$ & $\phi_{m, 4}=0$ & $\phi_{p, 4}=0$ & $\delta_{E}=0.52$ & \\
\hline$\xi_{r}=0.04$ & $\phi_{r, 5}=0$ & $\phi_{m, 5}=0$ & $\phi_{p, 5}=0$ & $1+g=1.02^{10}$ & \\
\hline \multicolumn{6}{|l|}{$\beta_{r}=1.35$} \\
\hline \multicolumn{6}{|l|}{$\beta_{m}=0.61$} \\
\hline$\beta_{p}=0.66$ & & & & & \\
\hline
\end{tabular}

Table 7: Calibrated Parameter Values 


\begin{tabular}{|c|c|c|c|c|c|c|c|c|c|}
\hline \multirow[b]{2}{*}{ Age } & \multicolumn{3}{|c|}{ Spending Adjusts } & \multicolumn{3}{|c|}{ Taxes Adjust } & \multicolumn{3}{|c|}{ Pensions Adjust } \\
\hline & Poor & Middle & Rich & Poor & Middle & Rich & Poor & Middle & Rich \\
\hline$<35$ & 0.62 & 0.61 & -1.66 & 3.77 & 3.87 & -0.57 & 0.64 & 0.62 & -1.45 \\
\hline $35-44$ & 0.09 & 11.05 & 2.73 & 3.67 & 14.55 & 3.60 & 0.37 & 11.21 & 2.86 \\
\hline $45-54$ & -1.05 & 10.02 & -2.33 & 1.64 & 13.02 & -1.98 & -0.25 & 10.51 & -2.19 \\
\hline $55-64$ & -3.17 & 3.12 & -3.40 & -1.84 & 4.71 & -3.22 & -0.39 & 4.72 & -3.20 \\
\hline $65-74$ & -9.92 & -0.78 & -5.42 & -9.79 & -0.57 & -5.25 & 2.86 & 6.62 & -4.90 \\
\hline$\geq 75$ & -12.45 & -6.67 & -4.97 & -12.19 & -6.32 & -4.43 & 0.29 & 0.96 & -4.65 \\
\hline Total & & 0.17 & & & 2.28 & & & 2.24 & \\
\hline
\end{tabular}

Table 8: Welfare Effects based on Redistribution in 1989 for Different Fiscal Policies, Full Surprise Experiment, Public Debt Returns to Steady State

\begin{tabular}{|c|c|c|c|c|c|c|c|c|c|}
\hline \multirow[b]{2}{*}{ Age } & \multicolumn{3}{|c|}{ Spending Adjusts } & \multicolumn{3}{|c|}{ Taxes Adjust } & \multicolumn{3}{|c|}{ Pensions Adjust } \\
\hline & Poor & Middle & Rich & Poor & Middle & Rich & Poor & Middle & Rich \\
\hline$<35$ & 0.16 & 0.16 & -0.67 & 1.43 & 1.47 & -0.25 & 0.17 & 0.16 & -0.59 \\
\hline $35-44$ & -0.10 & 3.91 & 0.72 & 1.36 & 5.35 & 1.07 & 0.01 & 3.98 & 0.76 \\
\hline $45-54$ & -0.69 & 4.13 & -1.37 & 0.40 & 5.36 & -1.26 & -0.39 & 4.31 & -1.33 \\
\hline $55-64$ & -0.95 & 1.26 & -1.97 & -0.42 & 1.91 & -1.93 & 0.12 & 1.87 & -1.90 \\
\hline 65-74 & -2.32 & -0.18 & -1.95 & -2.27 & -0.11 & -1.90 & 2.83 & 2.80 & -1.74 \\
\hline$\geq 75$ & -1.94 & -1.88 & -2.20 & -1.81 & -1.73 & -1.98 & 3.23 & 1.22 & -2.06 \\
\hline Total & & 0.22 & & & 1.09 & & & 1.01 & \\
\hline
\end{tabular}

Table 9: Welfare Effects based on Redistribution in 1989 for Different Fiscal Policies, Indexing ASAP Experiment, Public Debt Returns to Steady State 


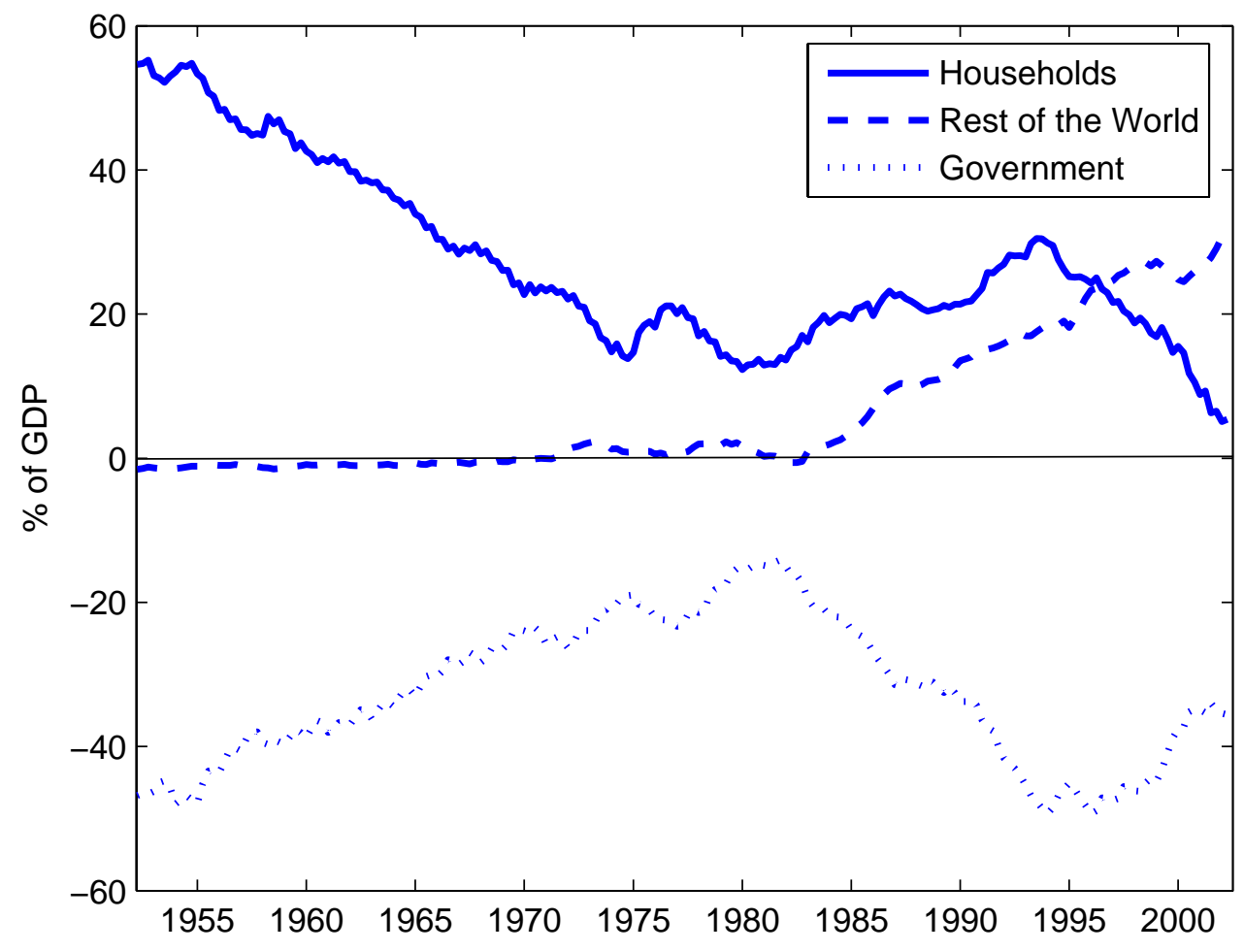

Figure 1: Net Nominal Positions, Sector Aggregates 

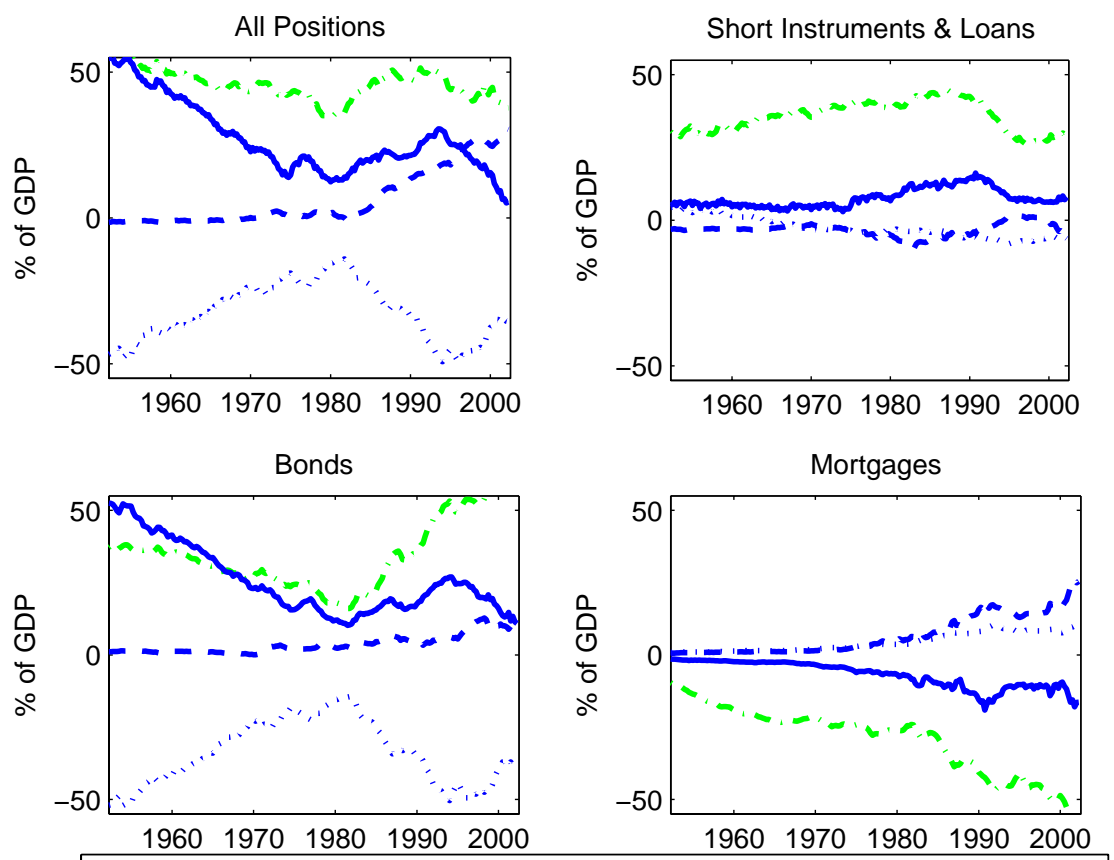

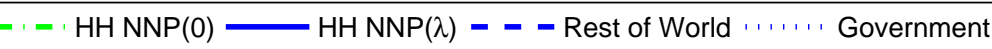

Figure 2: Net Nominal Positions, Sector Aggregates by Instrument


Figure 3: Inflation Expectation Factors for Redistribution Experiments 

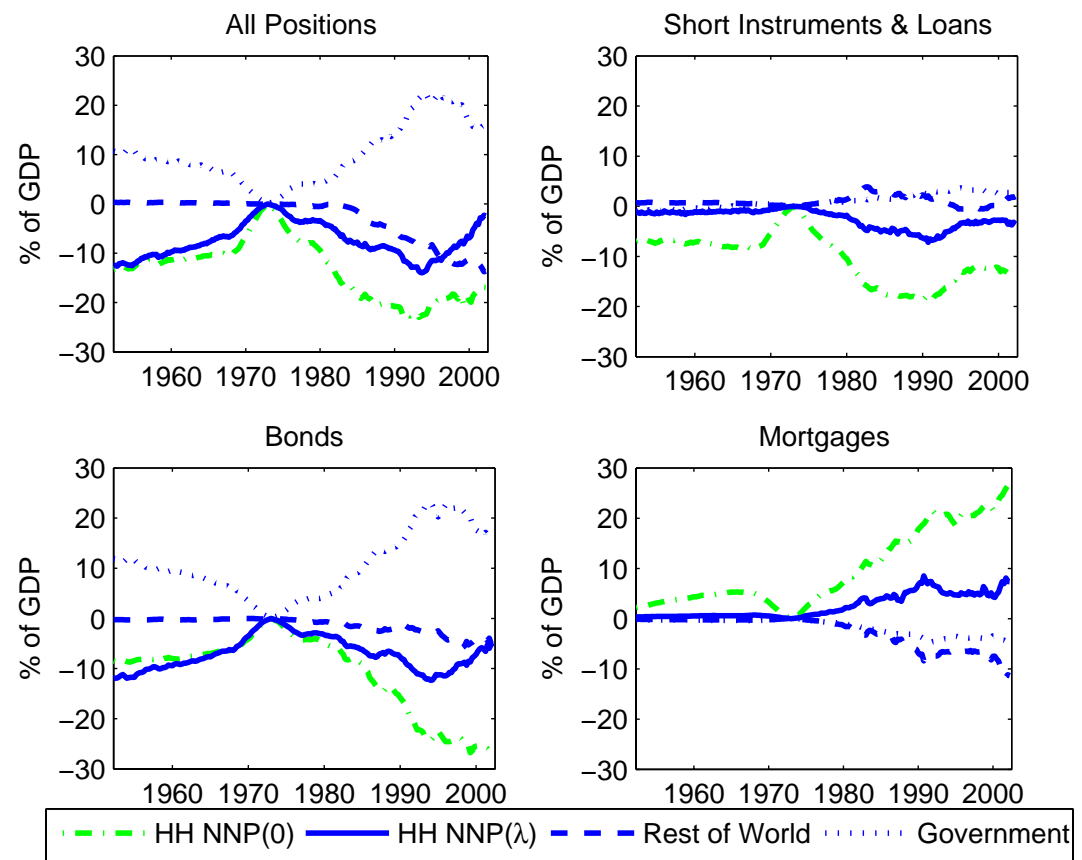

Figure 4: Full Surprise Experiment, Redistribution across Sectors over Time
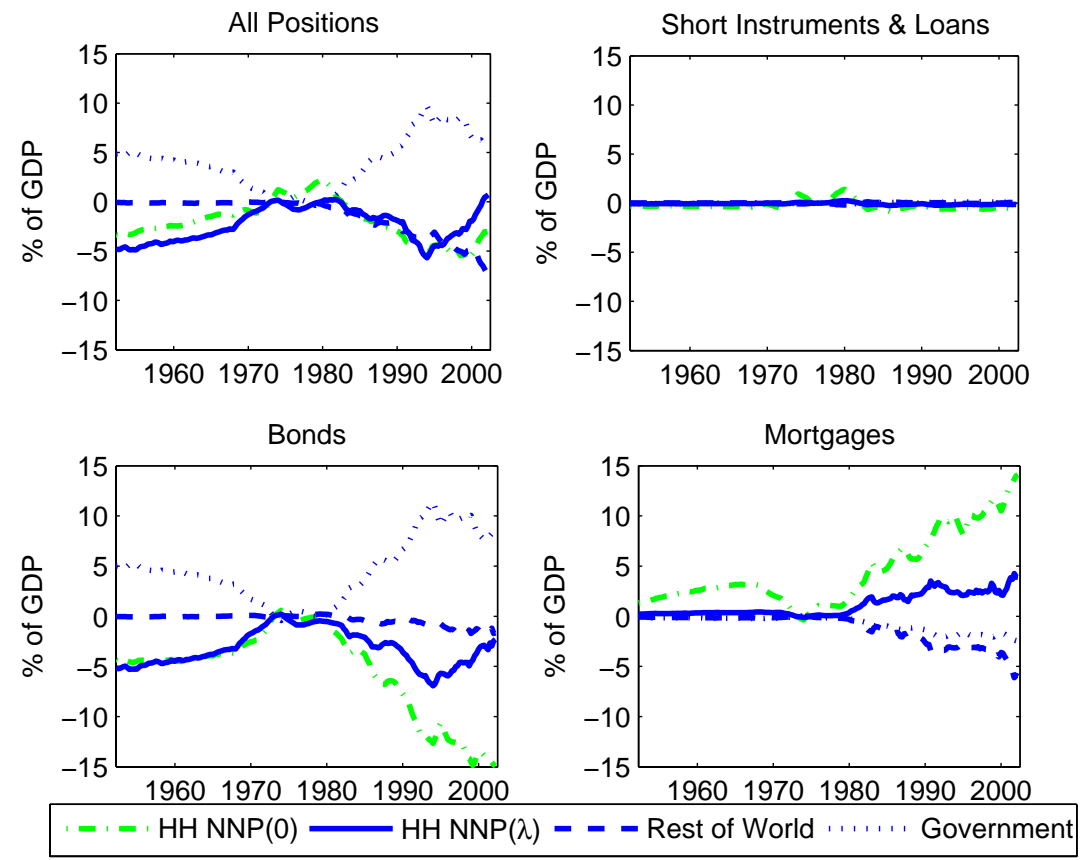

Figure 5: Indexing ASAP Experiment, Redistribution across Sectors over Time 

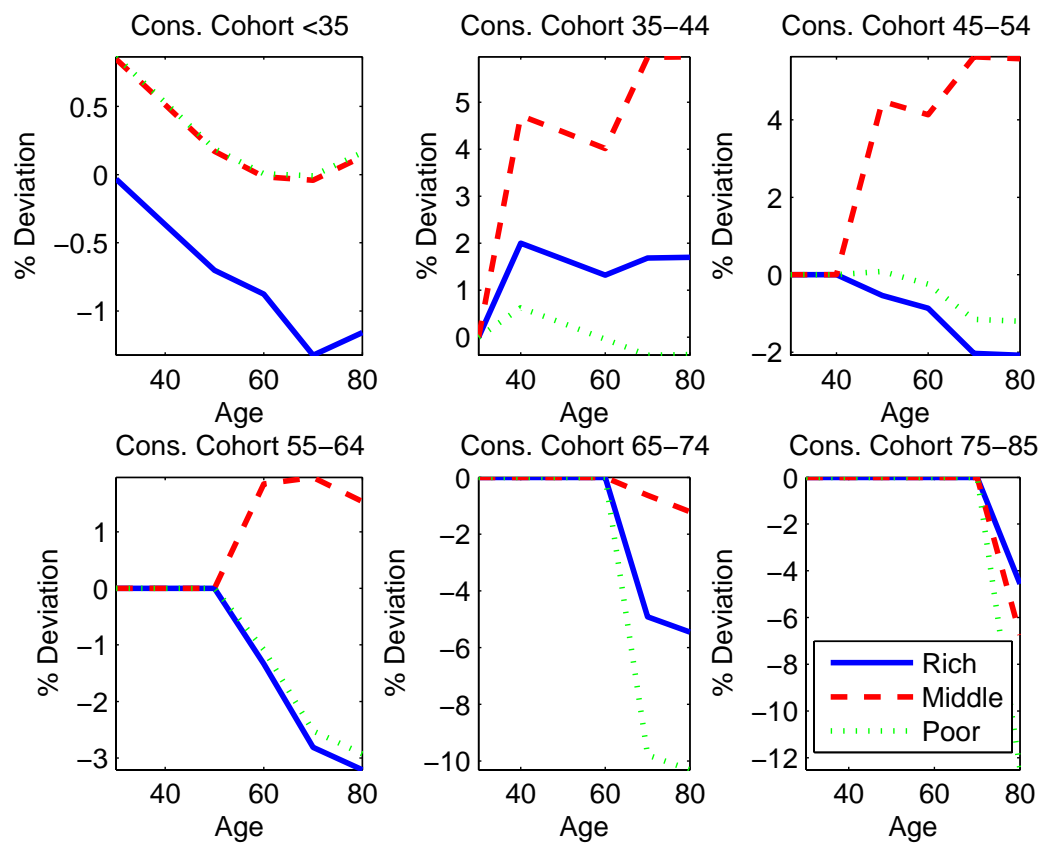

Figure 6: Impact on Lifetime Consumption, in Percent Deviation from Balanced Growth Path, based on Redistribution in 1989, Full Surprise Experiment
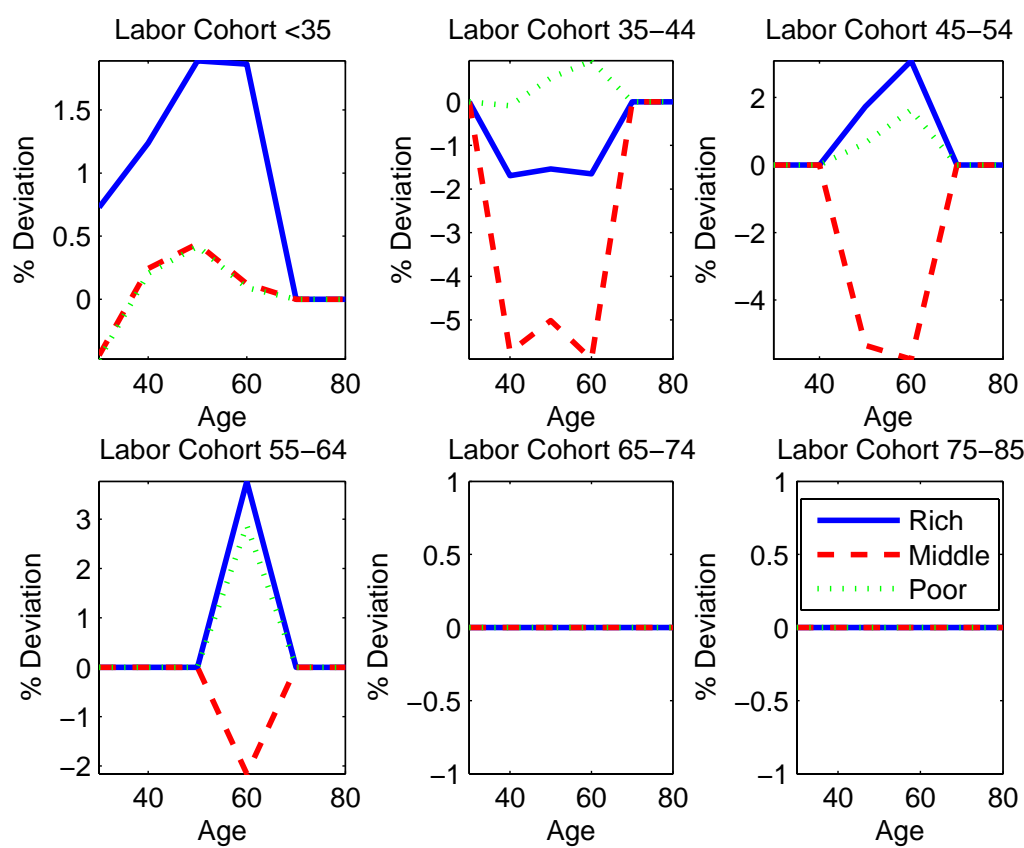

Figure 7: Impact on Lifetime Labor Supply, in Percent Deviation from Average Labor Supply on Balanced Growth Path, based on Redistribution in 1989, Full Surprise Experiment 

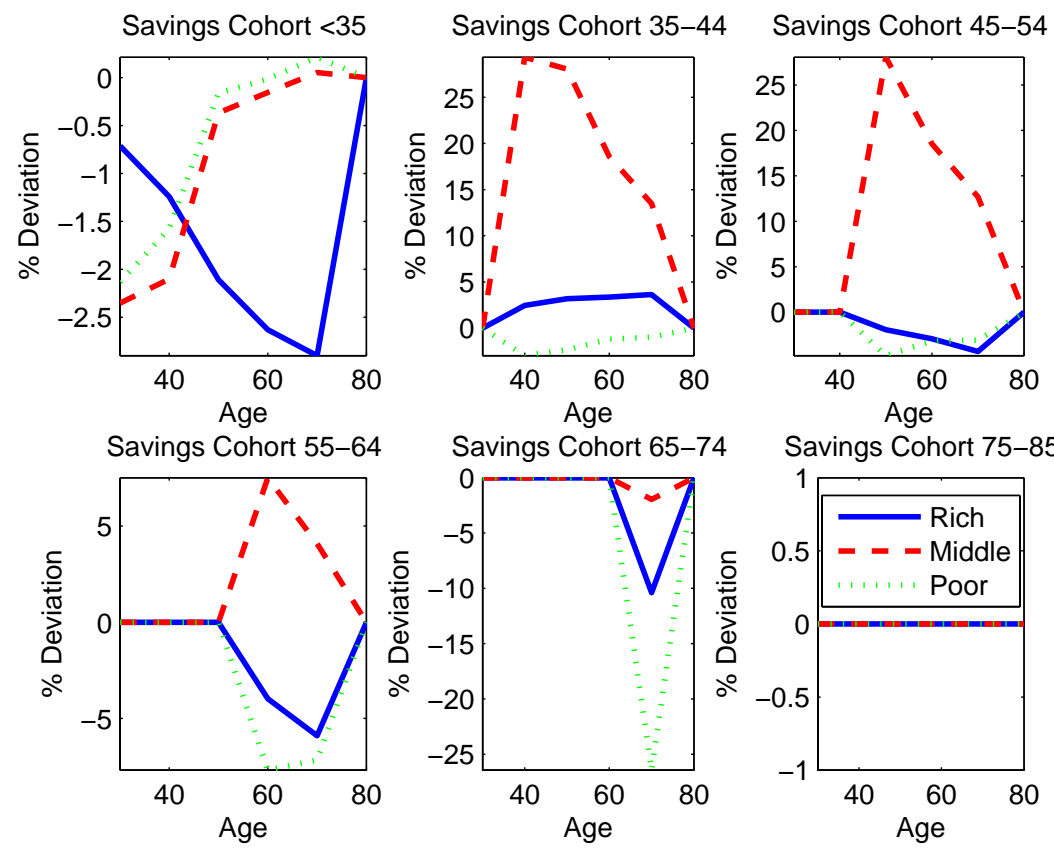

Figure 8: Impact on Lifetime Savings, in Percent Deviation from Average Savings on Balanced Growth Path, based on Redistribution in 1989, Full Surprise Experiment
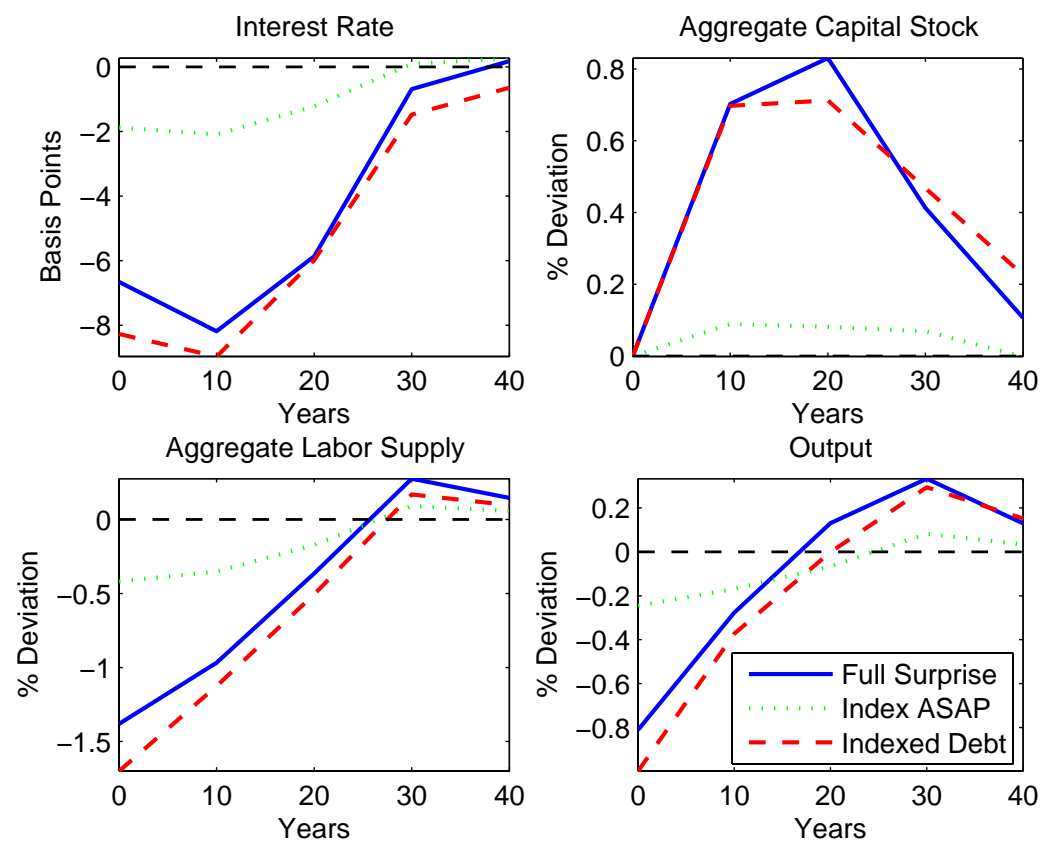

Figure 9: Impact on Economic Aggregates, in Basis Points (Interest Rate) and Percent Deviation from Balanced Growth Path (other Variables), based on Redistribution in 1989 

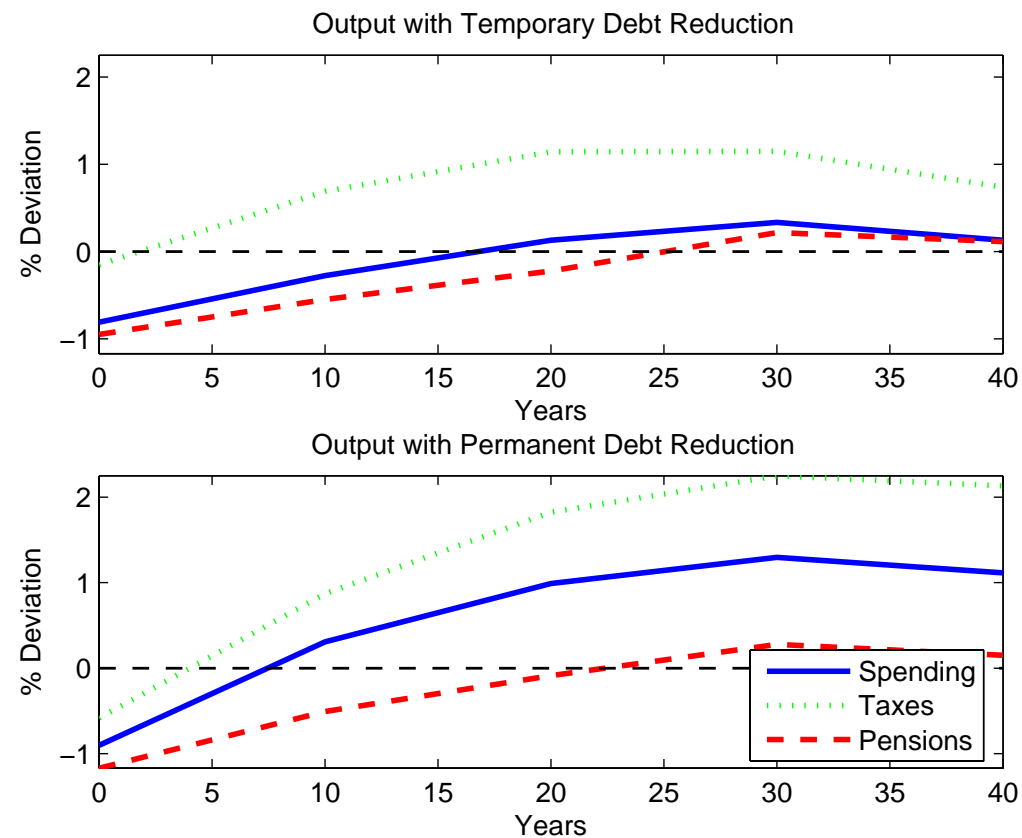

Figure 10: Impact on Aggregate Output by Policy Experiment, in Percent Deviation from Balanced Growth Path, based on Redistribution in 1989, Full Surprise Experiment
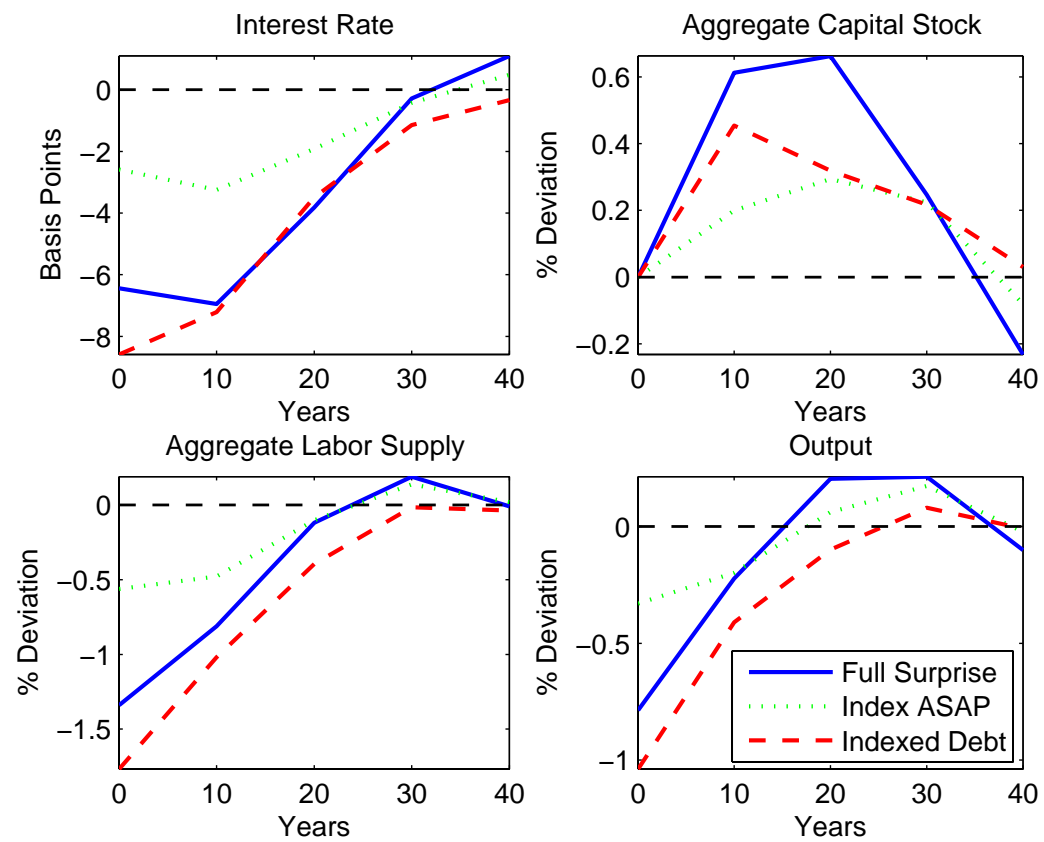

Figure 11: Impact on Economic Aggregates, in Basis Points (Interest Rate) and Percent Deviation from Balanced Growth Path (other Variables), based on Redistribution in 2001 